\title{
Fuzzy Determination of Target Shifting Time and Torque Control of Shifting Phase for Dry Dual Clutch Transmission
}

\author{
Zhiguo Zhao, Haijun Chen, and Yunyun Yang \\ School of Automotive Studies, Tongji University, Shanghai 201804, China \\ Correspondence should be addressed to Haijun Chen; chenhaijun312240@sina.com
}

Received 19 September 2013; Revised 5 November 2013; Accepted 5 November 2013; Published 11 February 2014

Academic Editor: Hui Zhang

Copyright (c) 2014 Zhiguo Zhao et al. This is an open access article distributed under the Creative Commons Attribution License, which permits unrestricted use, distribution, and reproduction in any medium, provided the original work is properly cited.

\begin{abstract}
Based on the independently developed five-speed dry dual clutch transmission (DDCT), the paper proposes the torque coordinating control strategy between engine and two clutches, which obtains engine speed and clutch transferred torque in the shifting process, adequately reflecting the driver intention and improving the shifting quality. Five-degree-of-freedom (DOF) shifting dynamics model of DDCT with single intermediate shaft is firstly established according to its physical characteristics. Then the quantitative control objectives of the shifting process are presented. The fuzzy decision of shifting time and the model-based torque coordinating control strategy are proposed and also verified by simulating under different driving intentions in up-/downshifting processes with the DCT model established on the MATLAB/Simulink. Simulation results validate that the shifting control algorithm proposed in this paper can not only meet the shifting quality requirements, but also adapt to the various shifting intentions, having a strong robustness.
\end{abstract}

\section{Introduction}

To improve Automatic Transmissions' shifting quality, the following measures are usually taken: (1) the timely and effective intervening of engine, namely, the decreasing torque request signal, is given by Transmission Control Unit to Engine Electronic Control Unit in the up- or downshifting process to cut off the fuel injection or delay the response of ignition advance angle, thus obtaining a reduced torque transmitted by hydraulic torque converter; (2) the switch of hydraulic torque converter's working state, that is, the hydraulic torque converter, transfers from "locking" state to "unlocking" state to realize hydraulic transmission in the shifting process; (3) the adjusting of engaging pressure, which means actively adjusting the pressure of main oil line in different conditions according to the engine load change to ensure the shifting feel; (4) the working sequence's match of wet clutch in planetary transmission and brake, thus avoiding shifting overlapping and power interruption; (5) the adoption of shifting actuator equipped with electromagnetic valve and buffer valve. Compared with the AT, the torsion damper in clutch driven plate of dry dual clutch transmission cannot absorb the whole shifting impact without the aid of hydraulic torque converter, thus deteriorating the shifting feel. Meanwhile, the shifting process completely depends on the switch of dual clutches' working state and engine torque active control. Once emerging the torque's inappropriate coordination between the dual clutch and engine, the power interruption, power cycle and large torque fluctuations of transmission output shaft would appear which not only directly influence the shifting comfort, but also cause the shock and vibration of transmission system thus reducing the longevity of drive components. Therefore, the control of shifting process becomes a difficult and key point of DDCT control.

Guo et al. [1] established a two-DOF shifting dynamics model and studied the fuzzy control of DCT shifting process. Considering the inertia, damping, and stiffness of transmission components, Zhang et al. established a five-DOF shifting dynamics model $[2,3]$. Goetz et al. $[4,5]$ and Qin et al. [6] divided the shifting process into torque phase which is used for the torque switch of dual clutch and inertia phase which is used to realize the synchronization of engine speed and clutch target speed. Besides, by controlling the throttle opening and the ignition advance angle, the engine speed was actively controlled to accelerate and ease the synchronization. 
Niu et al. [7] divided the upshifting process into five phases, namely, low gear operation phase, low gear torque phase, inertial phase, high gear torque phase, and high gear operation phase. Models of these phases were established with EASY5 software and the simulation of DCT shifting process was studied as well. However, the studies are only qualitative analysis, and the dual clutches' engaging extent varying with time of the dual clutch is not given quantitatively. Wu and Zhan [8] and Zhao et al. [9, 10] obtained the optimal engaging curves of dual clutch by using the linear quadratic optimal control and robust control theory, which provides the theoretical basis for the engineering application of dual clutch coordination control. However, the designing and solving of quadratic optimal control and robust control are difficult to be applied online in the DCT complex shifting process.

Thus based on the independently developed five-speed DDCT, five-DOF shifting dynamics models of DDCT with single intermediate shaft are established. According to the requirements of shifting quality, the quantitative control objectives of the shifting process are proposed. Based on the analysis of torque and speed characteristics of engine and dual clutch during the shifting process, the fuzzy time decision and the model-based torque coordinating control strategy are produced to solve the problem of torque coordination control of dual clutch and engine.

\section{Five-Speed Dry DCT Dynamics Equations}

2.1. Five-Speed Dry DCT Dynamic Model. The five-speed dry DCT described in the paper is a complex system, which is made up of dry dual clutch and its actuator, four synchronizers and their actuators, single intermediate shaft, and gear transmission mechanism. In order to study the dynamics characteristics of single clutch in the starting process and develop relevant coordinating control strategy, the following assumptions should be made before modeling:

(1) both wheels' moment of inertia and vehicle's translational weight are converted into the transmission output shaft. The engine output shaft and the input shaft and intermediate shaft and output shaft of the transmission are regarded as rigid body with distributed parameters, concentrated inertia, and friction damping;

(2) neglect the clutch actuator's and synchronizers' dynamics, as well as the heat fade of the clutch;

(3) neglect the elasticity between bearing and its block, as well as the elasticity and gap in gear engagement. The established five-speed dry DCT dynamics model after simplification is shown in Figure 1. The relevant parameters and variables are defined in the notation.

2.2. Shifting Dynamics Equations for Five-Speed Dry DCT. In essence, the shifting process of DCT is to switch the working state of dual clutch; that is, the previously engaged clutch disengages and the previously disengaged clutch engages at the same time. Among them, the working process of disengaged and engaged clutch can be divided into three
TABLE 1: Three phases in shifting process.

\begin{tabular}{ll}
\hline Three phases in shifting process & Main function \\
\hline Zero torque transfer phase & $\begin{array}{l}\text { Quickly eliminating the vacant } \\
\text { distance }\end{array}$ \\
Sliding friction phase & Torque and speed coordinating \\
Clutch fully engaged phase & Stable operation \\
\hline
\end{tabular}

phases (taking the engaging of clutch as an example) as shown in Table 1.

Zero Torque Transfer Phase. The vacant distance between the driving plate and driven plate is quickly eliminated.

Sliding Friction Phase. The clutch driving plate and driven plate begin to engage and transfer torque, and the torque is gradually increased until the synchronization of the driving plate and driven plate speed.

Clutch Fully Engaged Phase. The transmission is operating in certain gear stably.

Due to the small effect of clutch engaging and disengaging speed in zero torque transferred phase and clutch fully engaged phase on the shifting quality, the attention is only focused on torque coordinating control in sliding friction phase in the paper.

To further analyze the sliding friction phase, this phase is generally divided into torque phase and initial phase [6]. The torque phase is used for the torque switch of dual clutch and the inertia phase is used to realize the synchronization of engine speed and clutch target speed.

2.2.1. Shifting Dynamics Model of DCT in Sliding Friction Phase. Taking the shifting from 1st to 2nd gear speed as an example, in the DCT sliding friction phase, there exists a torque overlap between two clutches to transfer engine torque to the drive wheels, namely, $T_{c 1}$ decreases and $T_{c 2}$ increases gradually with the clutch 1 disengaging and, meanwhile, clutch 2 engaging little by little. It should be noted that the power cycle may occur in the DCT shifting phase, so the direction of clutch torque is determined by the sign of the error of the clutch driving and driven plate speed. Finally the shifting dynamics model of DCT in sliding friction phase can be obtained by its dynamic analysis:

$$
\begin{gathered}
I_{e} \dot{\omega}_{e}=T_{e}-\operatorname{sgn}\left(\omega_{e}-\omega_{c 1}\right) T_{c 1}-\operatorname{sgn}\left(\omega_{e}-\omega_{c 2}\right) T_{c 2}-b_{e} \omega_{e} \\
I_{c 1} \dot{\omega}_{c 1}=\operatorname{sgn}\left(\omega_{e}-\omega_{c 1}\right) T_{c 1}-T_{m c 1}-b_{c 1} \omega_{c 1} \\
\left(I_{c 2}+I_{g 2}\right) \dot{\omega}_{c 2}=\operatorname{sgn}\left(\omega_{e}-\omega_{c 2}\right) T_{c 2}-T_{m c 2}-b_{c 2} \omega_{c 2} \\
\left(I_{m}+I_{g 1}\right) \dot{\omega}_{m}=T_{c 1 m}+T_{c 2 m}-T_{s m}-b_{m} \omega_{m} \\
I_{s} \dot{\omega}_{s}=T_{m s}-T_{f}-b_{s} \omega_{s}
\end{gathered}
$$




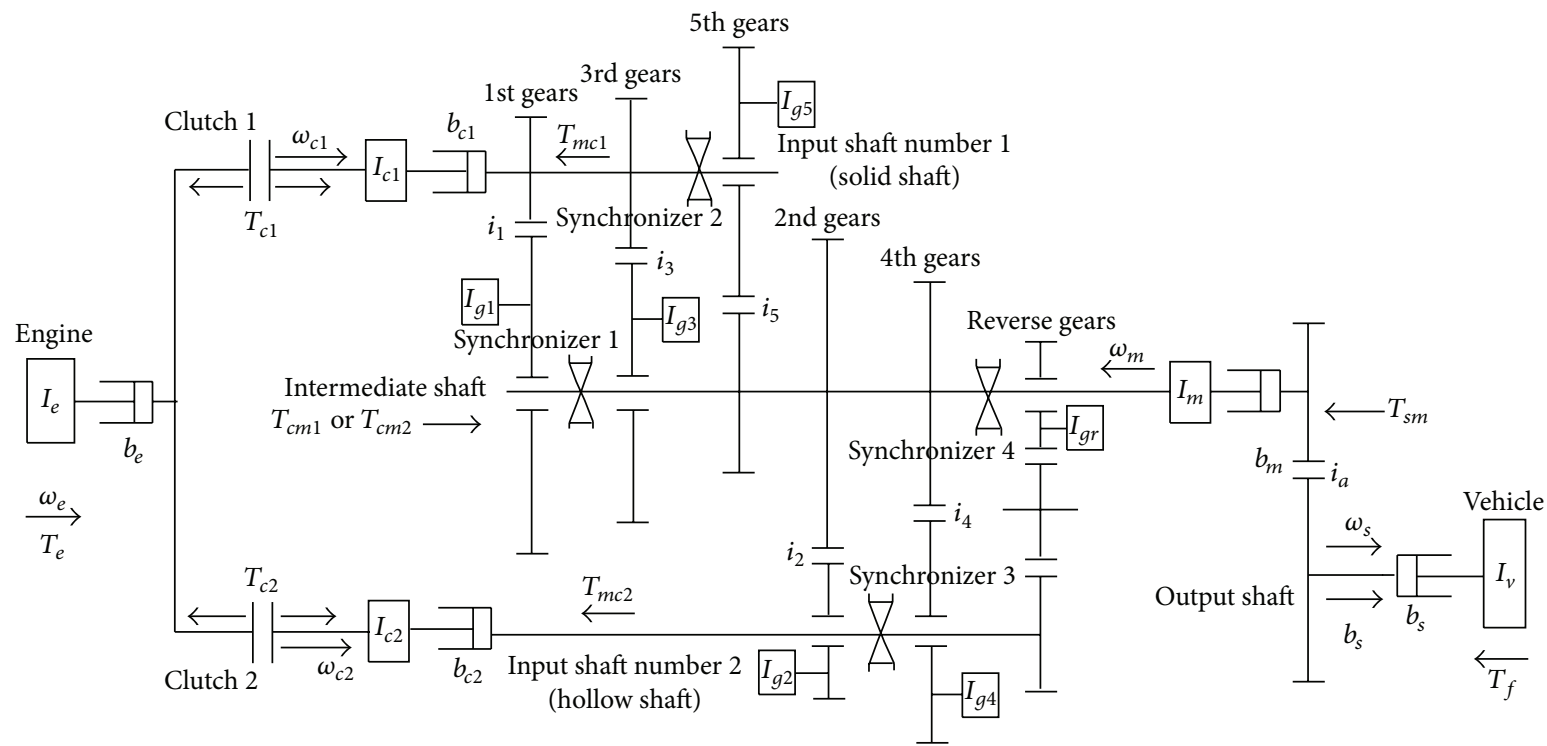

FIGURE 1: Five-speed dry DCT dynamics model.

where

$$
\begin{gathered}
T_{c 2}=\left\{\begin{array}{c}
\frac{2}{3}\left(\frac{R_{0}^{3}-R_{1}^{3}}{R_{0}^{2}-R_{1}^{2}}\right) \mu_{2} F\left(x_{2}\right), \quad \omega_{c 2} \leq \omega_{e}, \\
T_{c 2}^{L},
\end{array} \quad \omega_{c 2}=\omega_{e},\right. \\
T_{e}=f\left(\alpha, \omega_{e}\right), \quad T_{c 1 m}=T_{m c 1} i_{1} \eta, \\
T_{c 2 m}=T_{m c 2} i_{2} \eta, \quad T_{m s}=T_{s m} i_{a} \eta, \\
T_{f}=\left(\frac{C_{d} A}{21.15} v^{2}+m g \sin \theta+m g \cos \theta f+\delta m \frac{d v}{d t}\right) R_{w} \\
\delta=1+\frac{1}{m} \frac{I_{c 1} i_{1}^{2} i_{a}^{2}+I_{m} i_{a}^{2}+I_{s}+I_{v}}{r^{2}},
\end{gathered}
$$

where sgn is symbolic function, and its expression is

$$
\operatorname{sgn}\left(\omega_{e}-\omega_{c i}\right)=\left\{\begin{array}{ll}
1, & \omega_{e} \geq \omega_{c i}, \\
-1, & \omega_{e}<\omega_{c i},
\end{array} \quad i=1,2 .\right.
$$

Assume that

$$
\omega_{m}=\omega_{s} i_{a}=\frac{\omega_{c 1}}{i_{1}}=\frac{\omega_{c 2}}{i_{2}} .
$$

So the five-DOF model shown in (1) can be simplified to the following two-DOF model:

$$
\begin{gathered}
I_{e} \dot{\omega}_{e}=T_{e}-\operatorname{sgn}\left(\omega_{e}-\omega_{c 1}\right) T_{c 1}-\operatorname{sgn}\left(\omega_{e}-\omega_{c 2}\right) T_{c 2}-b_{e} \omega_{e} \\
I_{s}^{\mathrm{equ}} \dot{\omega}_{s}=\operatorname{sgn}\left(\omega_{e}-\omega_{c 1}\right) T_{c 1} K_{c 1} \\
\quad+\operatorname{sgn}\left(\omega_{e}-\omega_{c 2}\right) T_{c 2} K_{c 2}-T_{f}-b_{s}^{\mathrm{equ}} \omega_{s}
\end{gathered}
$$

where $I_{s}^{\text {equ }}, b_{s}^{\text {equ }}$ are the equivalent moment of inertia and rotating viscous damping coefficient, respectively; $K_{c 1}, K_{c 2}$ are magnification factors of the torque transferred by clutch 1 and clutch 2, respectively, both of which are equivalently converted to the transmission output shaft; that is,

$$
\begin{gathered}
I_{s}^{\mathrm{equ}}=I_{s}+\left(I_{m}+I_{g 1}\right) i_{a}^{2} \eta+I_{c 1} i_{1}^{2} i_{a}^{2} \eta^{2}+\left(I_{c 2}+I_{g 2}\right) i_{2}^{2} i_{a}^{2} \eta^{2}, \\
b_{s}^{\mathrm{equ}}=b_{s}+b_{m} i_{a}^{2} \eta+b_{c 1} i_{1}^{2} i_{a}^{2} \eta^{2}+b_{c 2} i_{2}^{2} i_{a}^{2} \eta^{2}, \\
K_{c 1}=i_{1} i_{a} \eta^{2}, \\
K_{c 2}=i_{2} i_{a} \eta^{2} .
\end{gathered}
$$

\subsubsection{Dynamics Model of DCT In-Gear Stable Operation} Phase. Still taking the shifting from 1st to 2 nd gear speed as an example, the speed of engine is equal to that of the engaged clutch driven plate before and after the shifting process. Based on this constrain, dynamics model of DCT in-gear stable operation can be obtained from (6). The dynamics model of DCT in 1st speed gear stable operation is

$$
I_{s}^{\mathrm{equ} 1} \dot{\omega}_{s}=T_{e} K_{e 1}-T_{f}-b_{s}^{\mathrm{equ} 1} \omega_{s}
$$

The dynamics model of DCT in 2nd speed gear stable operation is

$$
I_{s}^{\text {equ2 }} \dot{\omega}_{s}=T_{e} K_{e 2}-T_{f}-b_{s}^{\text {equ2 }} \omega_{s}
$$

where $I_{s}^{\text {equ1 }}, I_{s}^{\text {equ2 }}$ are equivalent moment of inertia in 1st and 2 nd gear speed in stable operation, respectively; $b_{s}^{\text {equ1 }}, b_{s}^{\text {equ2 }}$ are equivalent rotating viscous damping coefficient in 1st and 2nd gear speed in stable operation, respectively; $K_{e 1}, K_{e 2}$ are the magnification factors of the torque output by engine in 1st and 2 nd gear speed in stable operation, respectively, both of 
which are equivalently converted to the transmission output shaft; that is,

$$
\begin{gathered}
I_{s}^{\mathrm{equ} 1}=I_{s}+\left(I_{m}+I_{g 1}\right) i_{a}^{2} \eta+\left(I_{c 1}+I_{e}\right) i_{1}^{2} i_{a}^{2} \eta^{2} \\
+\left(I_{c 2}+I_{g 2}\right) i_{2}^{2} i_{a}^{2} \eta^{2}, \\
I_{s}^{\mathrm{equ} 2}=I_{s}+\left(I_{m}+I_{g 1}\right) i_{a}^{2} \eta+I_{c 1} i_{1}^{2} i_{a}^{2} \eta^{2}+\left(I_{c 2}+I_{g 2}+I_{e}\right) i_{2}^{2} i_{a}^{2} \eta^{2} \\
b_{s}^{\mathrm{equ} 1}=b_{s}+b_{m} i_{a}^{2} \eta+\left(b_{c 1}+b_{e}\right) i_{1}^{2} i_{a}^{2} \eta^{2}+b_{c 2} i_{2}^{2} i_{a}^{2} \eta^{2} \\
b_{s}^{\mathrm{equ} 2}=b_{s}+b_{m} i_{a}^{2} \eta+b_{c 1} i_{1}^{2} i_{a}^{2} \eta^{2}+\left(b_{c 2}+b_{e}\right) i_{2}^{2} i_{a}^{2} \eta^{2} \\
K_{e 1}=i_{1} i_{a} \eta^{2} \\
K_{e 2}=i_{2} i_{a} \eta^{2} .
\end{gathered}
$$

It should be noted that the dynamic characteristics of the synchronizer are not considered in the dynamics model above for its small effect on shifting quality. That means the 2nd speed gear has already been engaged before the shifting process and the 1st speed gear is still engaging after the shifting process. In addition, the shifting dynamics model of DCT in other speed gears can be obtained in the similar method of the shifting from 1st speed gear to 2 nd speed gear.

\section{Objectives of Shifting Control and Shifting Process Analysis}

3.1. Shifting Quality. The Shock intensity and sliding friction work are usually used to evaluate the shifting quality. And the Shock intensity in the sliding friction phase can be expressed as

$$
j=\frac{r}{i_{a} I_{s}} \frac{d T_{m s}}{d t}=\frac{r}{i_{a} I_{s}}\left(i_{1} \frac{d T_{c 1}}{d t}+i_{2} \frac{d T_{c 2}}{d t}\right) .
$$

It can be noticed from (10) that the Shock intensity $j$ is proportional to the derivative of the transmission output torque $T_{m s}$; meanwhile $T_{m s}$ is determined by the torque transferred by clutch 1 and clutch 2 . Therefore, in theory, if the torque transferred by the dual clutch satisfies a certain relationship, namely, $d T_{m s} / d t=0$, the total output torque remains constant. That means the Shock intensity $j$ remains constant zero and no impact produced in the shifting process.

The Shock intensity is as follows at the moment when the clutch driving plate speed and driven plate speed is synchronized:

$$
\begin{aligned}
j & =\frac{i_{1} i_{a} r}{\Delta t}\left[\dot{\omega}_{c 1}\left(t^{+}\right)-\dot{\omega}_{c 1}\left(t^{-}\right)\right] \\
& =\frac{i_{1} i_{a} r}{\Delta t} \frac{I_{e}}{I_{e}+I_{c 1}^{\mathrm{equ}}}\left[\dot{\omega}_{e}\left(t^{-}\right)-\dot{\omega}_{c 1}\left(t^{-}\right)\right],
\end{aligned}
$$

where $\dot{\omega}_{c 1}\left(t^{-}\right), \dot{\omega}_{c 1}\left(t^{+}\right)$are the angular acceleration of clutch driven plate before and after the moment when the speed is synchronous; $\dot{\omega}_{e}\left(t^{-}\right)$is the angular acceleration of engine output shaft before the moment when the speed is synchronous; $t$ is the moment when the clutch driving plate speed and driven plate speed are synchronous; $\Delta t$ is the sampling time of angular acceleration, whose value is determined by the longitudinal vibration frequency range that human body can withstand, taking $\Delta t=20 \mathrm{~ms}$ in the paper [11].

Equation (11) obviously shows that, in order to reduce the impact of clutch driving and driven plate, it is necessary to minimize the difference of angular acceleration between them at the synchronous moment.

The sliding friction work in the shifting phase can be expressed as

$$
L=\int_{t_{0}}^{t_{f}}\left(T_{c 1}\left|\omega_{e}-\omega_{c 1}\right|+T_{c 2}\left|\omega_{e}-\omega_{c 2}\right|\right) d t,
$$

where $t_{0}, t_{f}$ are the moment when the shifting begins and ends, respectively.

Compared with the DCT starting process, the shifting time of DCT is shorter and the sliding friction work is less. Meanwhile, the sliding friction work is proportional to the shifting time approximately, so the shifting time can represent the slipping friction work generated during the shifting process. In this paper, the shifting time thus is regarded as the measure of slipping friction work, which means if the shifting time is within a reasonable range, the sliding friction work is acceptable. The domestic and international research shows that the shifting time of DCT is generally controlled within 0.5 to $0.8 \mathrm{~s}$ [12].

3.2. Objectives of Shifting Control. Based on the analysis of the shifting quality, the following quantitative shifting control objectives are obtained.

(1) Shifting without impact: during the entire shifting phase, the acceleration of the vehicle remains constant and the Shock intensity is identically equal to zero. Namely, $a=a^{\text {Init }}$ and $j \equiv 0$, where $a^{\text {Init }}$ is the vehicle acceleration in the shifting beginning moment.

(2) Reasonable shifting time: the shifting time needs to be shortened and satisfy $t \in[0.5,0.8]$ under the condition of meeting the driver's intention and vehicle and road conditions.

(3) Avoid the power cycle: it should be ensured that the engine speed is greater than or equal to the dual clutch driven plate speeds in sliding friction phase at the same time: $\omega_{e} \geq \omega_{c 1}$ and $\omega_{e} \geq \omega_{c 2}$.

\section{Shifting Fuzzy Time Strategy and Torque Coordinating Control}

The slip friction process control in the shifting process, as shown in Figure 4, can be specialized as first, according to the intention of the driver, vehicle states, and road conditions, the target shifting time is obtained through the fuzzy reasoning (including the torque phase time and the inertia phase time); second, the online genetic algorithm is adopted to optimize the torque phase time and inertial phase time; then the target speed of engine and the target angular acceleration of the two 


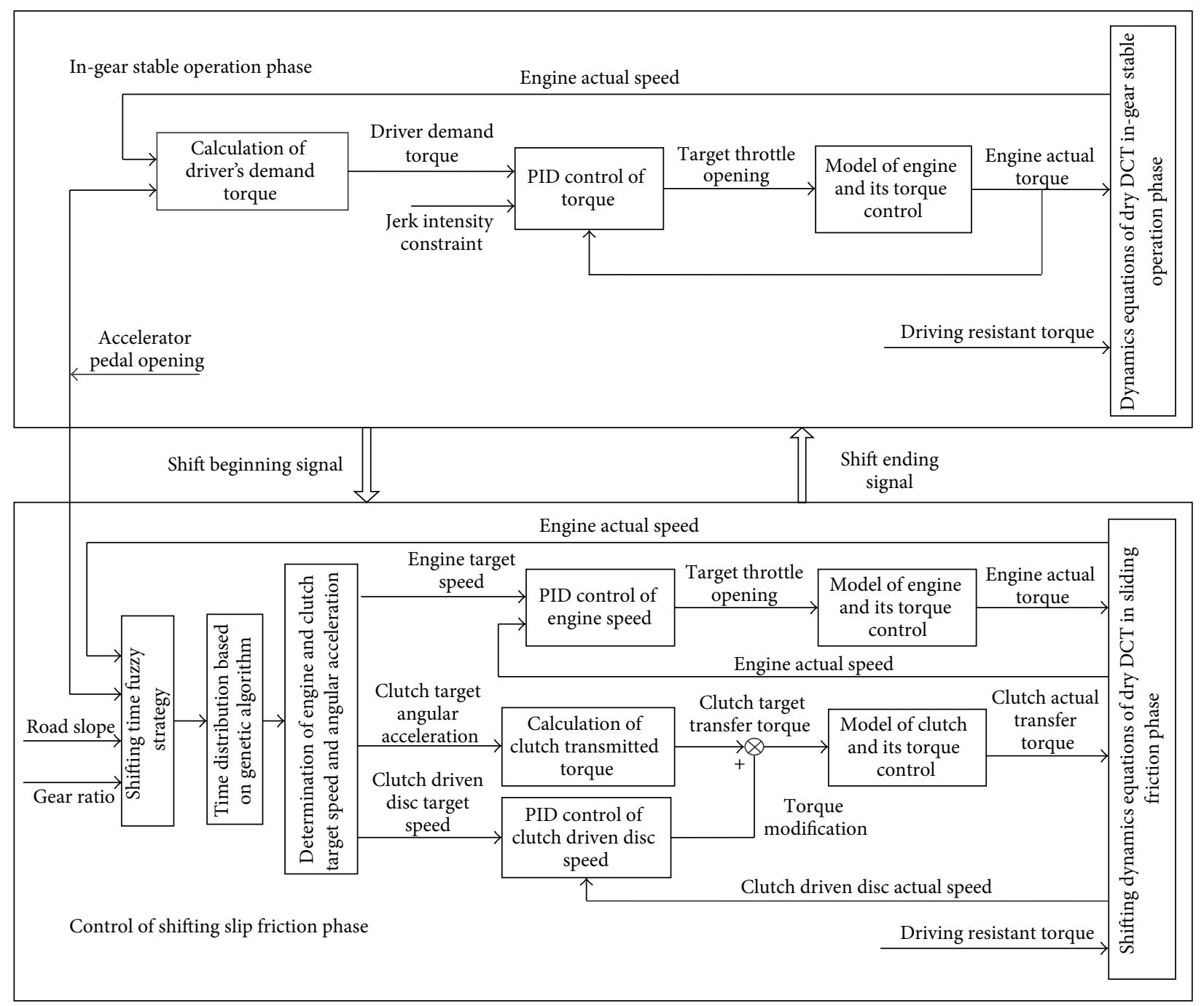

FIGURE 2: Shifting process control block diagram.

clutch driven plates are determined in the shifting process based on the shifting control quantitative targets; finally, the engine demand torque and the two clutches transmitted torque are calculated through the engine closed-loop control and model-based torque control.

"Shifting starting signal" in Figure 2 is determined by shifting schedule, and "shifting completing signal" refers to the speed synchronization signal of the engine and the clutch driven plate in upshifting process; meanwhile, it refers to the signal that the clutch separates and its torque becomes zero in downshifting process.

\subsection{Target Shifting Time Fuzzy Determination}

4.1.1. The Influence Factors of Shifting Time. Shifting time is affected and restricted by the factors as follows.

(1) Throttle opening and its changing rate: a relative big throttle opening and its changing rate indicate a shorter desired shifting time and vice versa; it means a longer desired shifting time.
(2) Engine output torque: the smaller the engine output torque is, the worse its load-carrying capacity is. And thus the clutch engaging process should slow down to avoid the flameout of the engine at the expense of shifting time. And when the engine output torque is relatively large, it accelerates the engaging process to shorten the shifting time.

(3) Transmission ratio changes before and after shifting: the greater the ratio changes before and after the shifting mean the bigger the vehicle longitudinal acceleration and dynamic load in the shifting process. To improve the shifting quality, slowing down the clutch engaging speed and extending the shifting time are required. Therefore, the shifting time from 1st speed gear to 2nd speed gear should be longer than from 2 nd to 3 rd.

(4) Road slope: the bigger the uphill road slope is, the smaller the engine backup power is. At this moment, a quick engagement would undoubtedly render a large shifting impact and may also lead to engine flameout. 


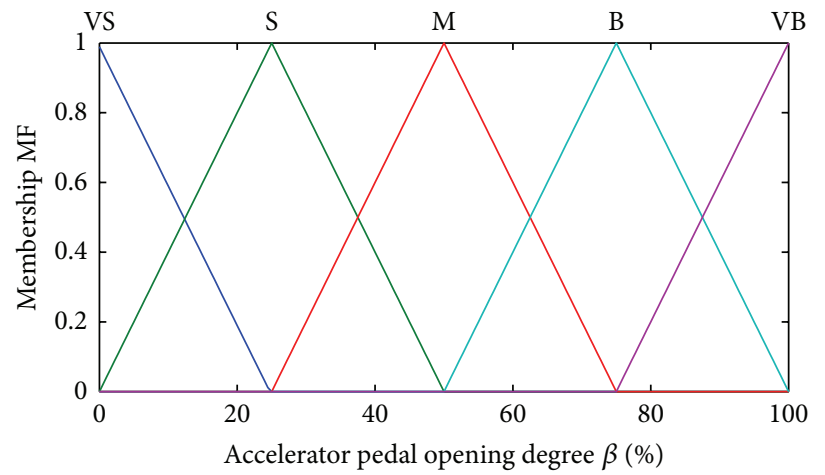

(a) Accelerator pedal opening degree membership function

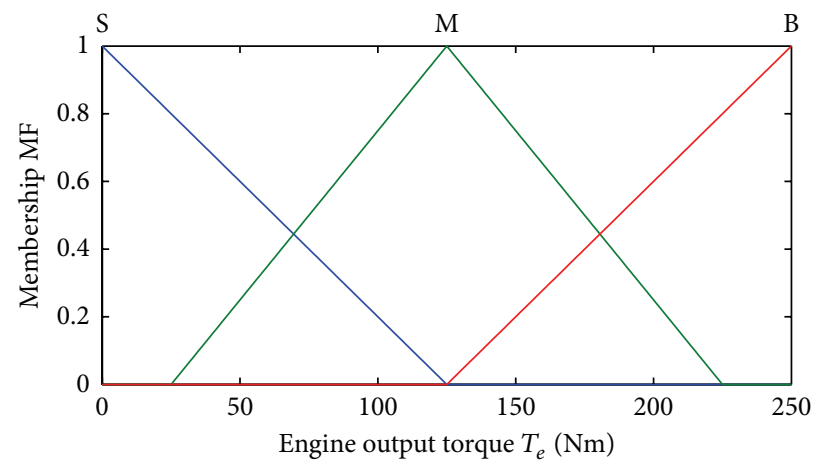

(c) Engine output torque membership function

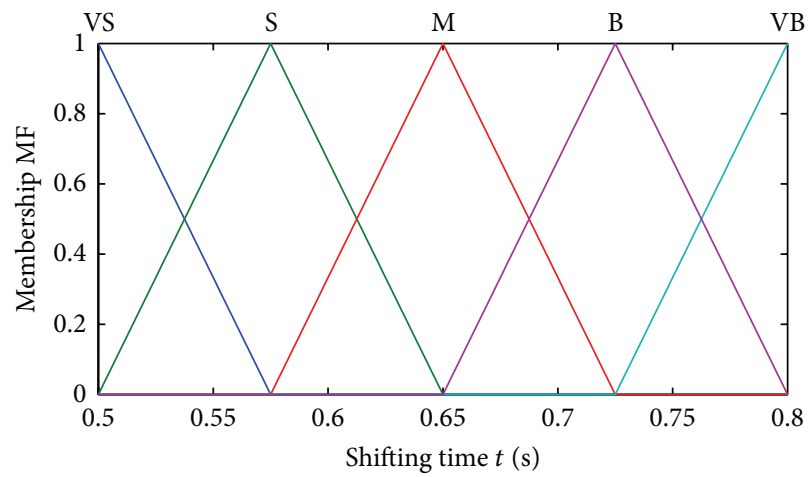

(e) Shifting time membership function

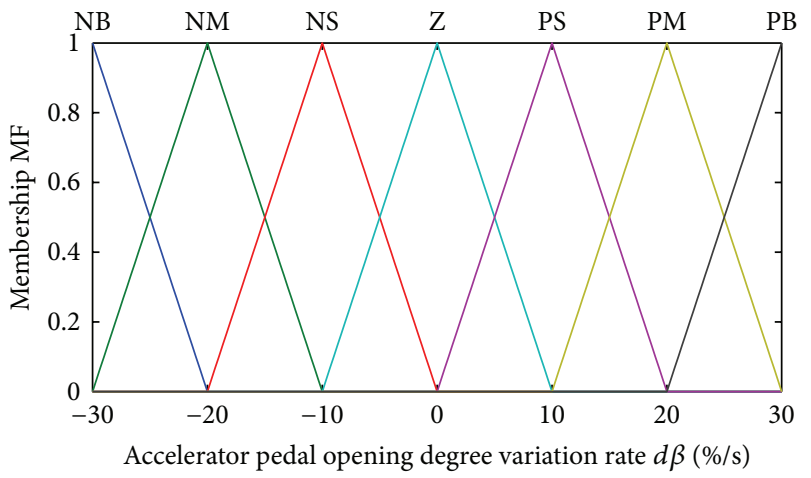

(b) Accelerator pedal opening degree variation rate membership function

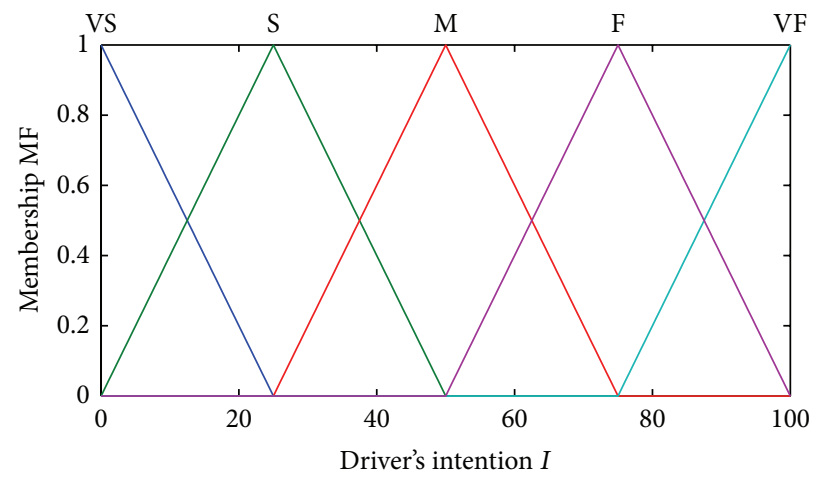

(d) Driver's intention membership function

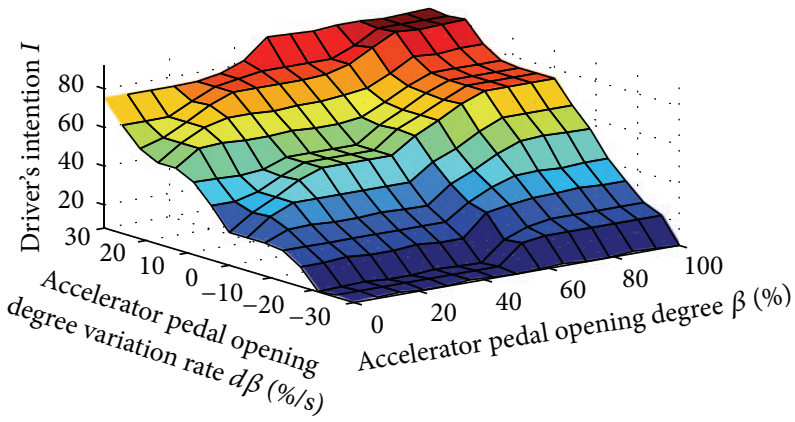

(f) Fuzzy controller input-output relationship of driver's intention

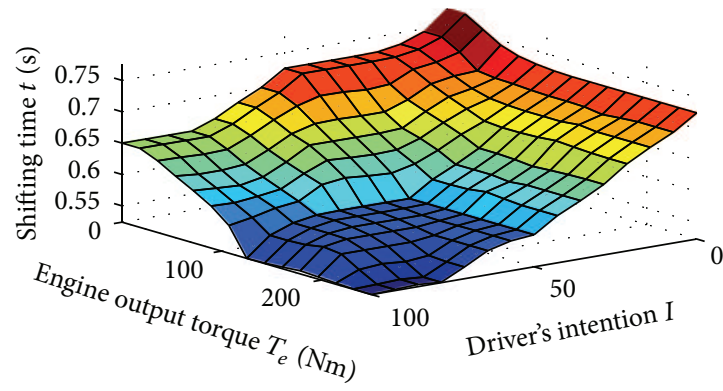

(g) Fuzzy controller input-output relationship of shifting time

Figure 3: Input and output membership functions and relations of shifting time fuzzy controller. 


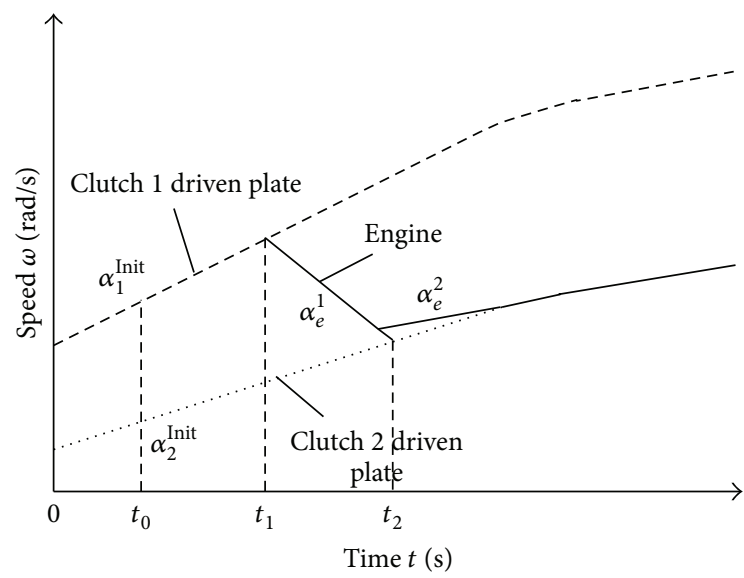

FIgURE 4: Target speed sketch map when upshifting.

Thus, the shifting time should be extended as the road gradient increases.

4.1.2. Shifting Time Fuzzy Reasoning [13]. Target shifting time should be determined by considering the combined effect of the above factors. However, in view of the realization, road slope is not taken into account. Besides, in order to overcome the shortcomings of large data store under multivariate [14], hierarchical fuzzy reasoning is adopted to determine the target shifting time. Firstly, the driver's intention is reasoned fuzzily by the accelerator pedal opening $\beta$ and its variation rate $\dot{\beta}$, and then the target shifting time is obtained by fuzzy reasoning, according to the driver's intention $I$ and engine target torque $I_{e}^{\text {ref }}$.

(1) Input language variable values and domains: accelerator pedal opening $\beta \in\{$ very small (VS), small (S), middle $(\mathrm{M})$, big $(\mathrm{B})$, very big $(\mathrm{VB})\}$; its domain is $[0 \sim$ 100]; its membership function is shown in Figure 3(a).

Accelerator pedal opening variation rate $\dot{\beta} \epsilon$ \{negative big (NB), negative middle (NM), negative small (NS), zero (Z), positive small (PS), positive middle (PM), positive big (PB) ; its domain is $[-50 \sim$ 50]; its membership function is shown in Figure 3(b).

Engine output torque $T_{e} \in\{$ small (S), middle (M), big (B)\}; its domain is [0 250]; its membership function is shown in Figure 3(c).

(2) Output language variable values and domains: driver's intention $I \in$ \{very slow (VS), slow (S), middle (M), fast (F), very fast (VF)\}; as for abstract quantity, its domain is [0 100]; its membership function is shown in Figure 3(d).

Shifting time $t \in\{$ very small (VS), small (S), middle (M), big (B), very big (VB) $\}$; its domain is $\{0.5 \sim 0.8\}$; its membership function is shown in Figure 3(e).

Its membership function is shown in Figure 3(b).

(3) Fuzzy reasoning rules table and mapping relationship between input and output variables: driver's intention
TABLE 2: Driver's intention fuzzy reasoning rules table (upshifting).

\begin{tabular}{lccccccc}
\hline Accelerator pedal & \multicolumn{6}{c}{ Accelerator pedal opening variation $\left(\% / \mathrm{s}^{2}\right)$} \\
opening & NB & NM & NS & Z & PS & PM & PB \\
\hline VS & VS & VS & VS & S & M & M & F \\
S & VS & VS & S & M & M & F & F \\
M & VS & VS & S & M & M & F & VF \\
B & VS & S & M & F & F & VF & VF \\
VB & VS & S & M & F & F & VF & VF \\
\hline
\end{tabular}

TABLE 3: Driver's intention fuzzy reasoning rules table (downshifting).

\begin{tabular}{lccccccc}
\hline \multirow{2}{*}{$\begin{array}{l}\text { Accelerator pedal } \\
\text { opening }\end{array}$} & Accelerator pedal opening variation rate $\left(\% / \mathrm{s}^{2}\right)$ \\
\hline VS & NB & NM & NS & Z & PS & PM & PB \\
S & VS & VS & VS & S & M & M & F \\
M & VS & VS & S & M & M & F & F \\
B & VS & VS & S & M & M & F & VF \\
VB & VS & S & M & F & F & VF & VF \\
\hline
\end{tabular}

TABLE 4: Shifting time fuzzy reasoning rules table.

\begin{tabular}{lccccc}
\hline Engine output torque & \multicolumn{5}{c}{ Accelerator pedal opening degree $\beta / \%$} \\
$T_{e}$ & VS & S & M & F & VF \\
\hline $\mathrm{S}$ & VB & B & B & M & M \\
M & B & M & S & S & VS \\
B & B & M & S & VS & VS \\
\hline
\end{tabular}

fuzzy reasoning rules and mapping relationship surfaces between input and output variables are shown in Tables 2 and 3 and Figure 3(f), respectively. Shifting time fuzzy reasoning rules mapping relationship surfaces between input and output variables are shown in Table 4 and Figure 3(g), respectively.

4.1.3. Time Distribution Based on Genetic Algorithm. The time distribution strategy between torque phase and inertial phase is based on genetic algorithm.

According to driving condition, vehicle condition, and road condition, the time amount of torque phase and inertial phase in the shifting process has been already determined, but the specified time distribution between them is still needed. What is more important is that the time distribution between the two phases determines the values of sliding friction work and impact degree and thus influences the shifting feeling. Focused on this problem, the real-time time distribution strategy between torque phase and inertial phase based on genetic algorithm is proposed in the following paper. The time variables $t_{1}-t_{0}$ and $t_{2}-t_{1}$ are obtained by minimizing the sliding friction work in the process from $t_{0}$ to $t_{2}$.

The fitness function is determined as follows. 
During the period of $t_{0}$ to $t_{2}$, only clutch 2 produces sliding friction work. In view of this, the sliding friction calculating equation is as follows:

$$
\begin{aligned}
W_{\min }= & \int_{t_{0}}^{t_{2}}\left(T_{c 2}\left|\omega_{e}^{\mathrm{ref}}-\omega_{c 2}^{\mathrm{ref}}\right|\right) d t \\
= & \int_{t_{0}}^{t_{1}}\left(T_{c 2}\left|\omega_{e}^{\mathrm{ref}}-\omega_{c 2}^{\mathrm{ref}}\right|\right) d t \\
& +\int_{t_{0}}^{t_{2}}\left(T_{c 2}\left|\omega_{e}^{\mathrm{ref}}-\omega_{c 2}^{\mathrm{ref}}\right|\right) d t .
\end{aligned}
$$

The quality of each solution is evaluated by the fitness function. The bigger the fitness function is, the better is the quality of the solution, therefore the genetic algorithm fitness function can be determined as follows:

$$
\text { fitness }=\frac{1}{W_{\min }} .
$$

The optimization variable is $t_{1}$ (where $t_{0}<t_{1}<t_{2}$ ). According to the principle of genetic algorithm, the optimal variable $t_{1}$ can be obtained after a certain amount of iterative computation, and then the torque phase and inertial phase time are obtained which are $t_{1}-t_{0}$ and $t_{2}-t_{1}$, respectively.

It is noteworthy that it is hard to guarantee the real-time adopting the online genetic algorithm, but the genetic algorithm has the characteristic of fast convergence on starting search. This paper has been verified by offline simulation and a superior optimal result will be obtained after a certain amount of iterative computation and thus by this way can resolve the problem of genetic algorithm online optimization which is hard to guarantee its real-time performance.

4.2. The Target Speed and the Angular Acceleration Determination. To the realization of "no impact shifting," the clutch 1 and clutch 2 driven plate in shifting process should maintain a constant angular acceleration. Combined with the shifting process characteristics described and the shifting time determined previously, the target speed curves of engine and clutch can be further obtained.

4.2.1. Upshifting Speed and Angular Acceleration Determination. Target speed in upshifting process is shown in Figure 4, where $t_{0}$ is the shifting start time; $t_{1}$ is the torque phase ending time; $t_{2}$ is the traditional inertial phase ending time; $\alpha_{1}^{\text {Init }}$, $\alpha_{2}^{\text {Init }}$ are the driven plate angular accelerations of clutch 1 and clutch 2 at the shifting beginning moment; $\alpha_{e}^{1}$ is engine target angular acceleration in the first stage of inertia phase; $\alpha_{e}^{2}$ is engine target angular acceleration in the slip friction stage of inertia phase.

From "no impact shifting" principle, the following equation can be obtained:

$$
\alpha_{1}=\alpha_{1}^{\text {Init }}, \quad \alpha_{2}=\alpha_{2}^{\text {Init }}
$$

In this equation, $\alpha_{1}, \alpha_{2}$ are the driven plate target angular accelerations of clutch 1 and clutch 2 in shifting process.
According to the "reduce or avoid power cycle" control target, in torque phase of upshifting process as shown in Figure 4, engine target speed should be bigger than or equal to clutch 1 driven plate target speed. For the convenience of calculation, assume that the two speeds are equal; that is,

$$
\omega_{e}=\omega_{c 1} \text {. }
$$

As depicted in Figure 4, the whole shifting time should be the sum of the torque phase time and the inertia phase time; that is,

$$
t=t_{2}-t_{0}
$$

The method to confirm the shifting time $t$ has been given in details in previous section. According to the preestablished time ratio of torque phase and inertial phase, the value of $\left(t_{1}-t_{0}\right)$ and $\left(t_{2}-t_{1}\right)$ can be determined. Based on the target angular acceleration and shifting time, the engine target speed at the moment $t_{1}$ and the driven plate target speed of clutch 2 at the moment $t_{2}$ can be obtained:

$$
\begin{gathered}
\omega_{e}\left(t_{1}\right)=\alpha_{1}^{\text {Init }}\left(t_{1}-t_{0}\right)+\omega_{e}\left(t_{0}\right), \\
\omega_{c 2}\left(t_{2}\right)=\alpha_{2}^{\text {Init }} t+\omega_{c 2}\left(t_{0}\right) .
\end{gathered}
$$

Here, $\omega_{e}\left(t_{0}\right), \omega_{c 2}\left(t_{0}\right)$ are the speed of engine and clutch 2 driven plate at shifting start moment.

To meet the requirement of speed synchronization, in the first stage of inertial phase, engine target angular acceleration is

$$
\alpha_{e}^{1}=\frac{\left[\omega_{e}\left(t_{1}\right)-\omega_{c 2}\left(t_{2}\right)\right]}{\left(t_{2}-t_{1}\right)} .
$$

To reduce the vehicle impact in the synchronization moment, the microslip friction stage is introduced to the inertia phase. The purpose of this phase is to accelerate the speed of the engine output shaft in order to make the angular acceleration between the engine output shaft and the clutch 2 driven plate as close as possible

$$
\alpha_{e}^{2}=\delta \alpha_{2}
$$

In this equation, the value of $\delta$ is within $[0,1]$. The bigger $\delta$ is, the smaller the angular acceleration deviation between engine and clutch 2 driven plate is at the synchronization moment. Besides, the impact will be smaller, but the synchronization time will increase. And vice versa a shorter synchronization time is needed but higher angular acceleration deviation and the impact. Therefore, it needs to weigh the effect of impact and the shifting time when choosing $\delta$.

In addition, in upshifting process, microslip friction stage begins when the following constrain is met:

$$
\left(\omega_{e}-\omega_{c 2}\right) \leq \omega_{\text {Const }} .
$$

In this equation, $\omega_{\text {Const }}$ is the speed deviation threshold.

Different values of $\delta$ and $\omega_{\text {Const }}$ will render the change of target curves in microslide friction stage, so the introduction of microslip friction can get relatively smaller impact by sacrificing a certain shifting time. 


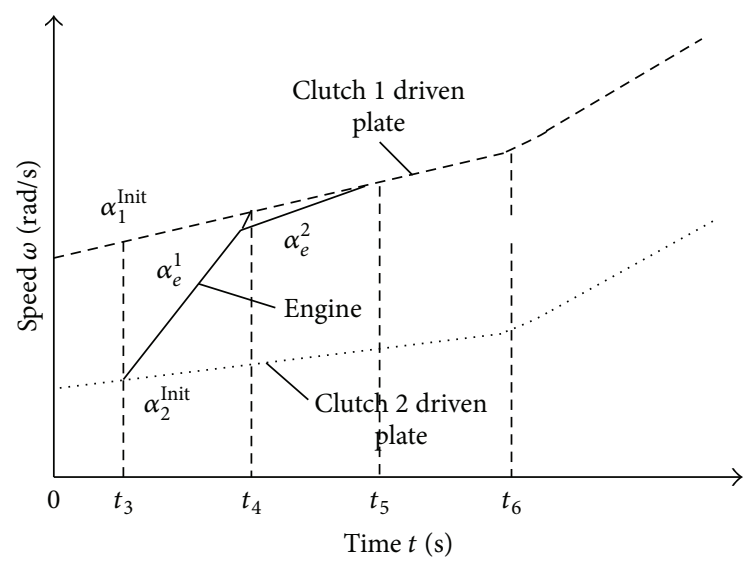

FIGURE 5: Target speed sketch map when downshifting.

4.2.2. Speed and Angular Acceleration Determination in the Downshifting Process. The target speed of downshifting process is shown in Figure $5 ; t_{3}$ is the shifting start time; $t_{4}$ is the inertial phase ending time; $t_{5}$ is the torque phase start time; $t_{6}$ is the torque phase ending time.

Similar to upshifting process, in downshifting process, driven plate target angular accelerations of clutch 1 and clutch 2 and the engine target speed in torque phase can also be obtained from (15) and (16).

The engine target speed at the moment $t_{3}$ and the driven plate target speed of clutch 2 at the moment $t_{4}$ are as follows:

$$
\omega_{e}\left(t_{3}\right)=\omega_{c 2}\left(t_{3}\right), \quad \omega_{c 1}\left(t_{4}\right)=\alpha_{2}^{\text {Init }}\left(t_{4}-t_{3}\right)+\omega_{c 1}\left(t_{3}\right) .
$$

The engine target angular acceleration in the first stage of inertial phase is

$$
\alpha_{e}^{1}=\frac{\left[\omega_{c 1}\left(t_{4}\right)-\omega_{e}\left(t_{3}\right)\right]}{\left(t_{4}-t_{3}\right)} .
$$

The engine target angular acceleration in slip friction stage of inertial phase is

$$
\alpha_{e}^{2}=\delta \alpha_{1}
$$

In downshifting process, microslip friction stage begins when the following constrain is met:

$$
\left(\omega_{c 1}-\omega_{e}\right) \leq \omega_{\text {Const }} .
$$

\subsection{The Target Torque Determination}

4.3.1. Engine Target Torque Determination. The PID control can be adopted to realize the closed-loop tracking of engine speed after the determination of engine target torque in the shifting process. The engine target torque is expressed as

$$
\begin{gathered}
e=\omega_{e}^{\mathrm{Tar}}-\omega_{e}, \\
\alpha=K_{P} e+K_{I} \int e d t+K_{D} \frac{d e}{d t}, \quad T_{e}=f\left(\alpha, \omega_{e}\right),
\end{gathered}
$$

where $\omega_{e}^{\text {Tar }}, \omega_{e}$ are the target and actual speed of engine respectively; $K_{P}, K_{I}, K_{D}$ are proportional, integral, and differential coefficients in the PID control of engine speed; $\alpha$ is the engine throttle opening.

4.3.2. The Calculation of Model-Based Target Torque Transferred by Clutch. After obtaining the target angular speed of engine and clutch's driven plate, the target torque transferred by clutch in the shifting process can be calculated as follows based on DCT dynamical model.

(1) Torque Phase in Upshifting Process. As shown in Figure 2, clutch 1's torque gradually declines to zero, while clutch 2's torque rises up synchronously in this phase. Provided that the shifting time $t$ has been predetermined and the time taken by torque phase and inertial phase is the same, the target torque of clutch 1 and clutch 2 can be gained based on the dynamics model expressed in (5):

$$
\begin{gathered}
T_{c 1}=T_{c 1}^{\text {Init }}-\int_{t_{0}}^{t_{1}} \frac{T_{c 1}^{\text {Init }}}{\left(t_{1}-t_{0}\right)} d \tau, \\
T_{c 2}=\frac{I_{\mathrm{s}}^{\mathrm{equ}} \alpha_{2} / i_{2} i_{a}+T_{f}+b_{\mathrm{s}}^{\mathrm{equ}} \omega_{s}-T_{c 1} K_{c 1}}{K_{c 2}},
\end{gathered}
$$

where $T_{c 1}^{\text {Init }}$ is the torque transfer by clutch 1 at the starting moment of shifting.

(2) Inertial Phase in Upshifting Process. The torque transfer by clutch 1 has already declined to zero in this phase; meanwhile, as for clutch 2, the torque remains constant; that is,

$$
T_{c 1}=0, \quad T_{c 2}=\frac{I_{s}^{\mathrm{equ}} \alpha_{2} / i_{2} i_{a}+T_{f}+b_{s}^{\mathrm{equ}} \omega_{s}-T_{c 1} K_{c 1}}{K_{c 2}} .
$$

(3) Inertial Phase in Downshifting Process. As the inertial phase in upshifting process, the torque transfer by clutch 1 and clutch 2 is as follows:

$$
T_{c 1}=0, \quad T_{c 2}=\frac{I_{s}^{\mathrm{equ}} \alpha_{2} / i_{2} i_{a}+T_{f}+b_{s}^{\mathrm{equ}} \omega_{s}-T_{c 1} K_{c 1}}{K_{c 2}} .
$$

(4) Torque Phase in Downshifting Process. As the torque phase in upshifting process, the torque transfer by clutch 1 and clutch 2 is as follows:

$$
\begin{gathered}
T_{c 1}=\frac{I_{s}^{\mathrm{equ}} \alpha_{1} / i_{1} i_{a}+T_{f}+b_{s}^{\mathrm{equ}} \omega_{s}-T_{c 2} K_{c 2}}{K_{c 2}}, \\
T_{c 2}=T_{c 2}^{\text {Init }}-\int_{t_{5}}^{t_{6}} \frac{T_{c 1}^{\text {Init }}}{\left(t_{6}-t_{5}\right)} d \tau
\end{gathered}
$$

where $T_{c 2}^{\text {Init }}$ is the torque transfer by clutch 2 at the zero hour of torque phase. 
4.3.3. The Modification of Desired Torque Transfer by Clutches. Considering that the above-mentioned desired torque is obtained based on DCT dynamics model, in the practical application, however, factors such as response characteristics of clutch actuator, parameter variation, and external disturbance ought to be fully taken into account. Thus a torque close-loop modification is applied, as expressed by the following equations:

$$
T_{c i}^{c}=T_{c i}^{o}+\Delta T_{c}, \quad i=1,2,
$$

where $T_{c i}^{o}$ is clutch's desired torque obtained from the model, $T_{c i}^{c}$ is the modified clutch torque, and $\Delta T_{c}$ is the torque modification in close-loop, as defined by the following equations:

$$
\begin{gathered}
e=\omega_{c}^{\mathrm{Tar}}-\omega_{c}, \\
\Delta T_{c}=k_{p} e+k_{i} \int e d t+k_{d} \frac{d e}{d t},
\end{gathered}
$$

where $\omega_{c}^{\text {Tar }}, \omega_{c}$ are the desired and actual speeds of clutch driven plate, respectively; $k_{p}, k_{i}, k_{d}$ are proportional, integral and differential coefficients in the PID control of clutch driven plate speed, respectively.

\section{Simulation Analysis and Results}

Based on the DCT dynamics model, fuzzy shifting time decision, and torque coordinating control strategies, the simulation model of shifting control in DCT vehicles is established on MATLAB/Simulink software platform and the upshifting and downshifting process are simulated and analyzed, respectively.

5.1. Simulation Analysis of Upshifting Process. In terms of upshifting process, the simulation is analyzed from three aspects: driver different shifting intentions, different speed gears shifting, and open-plus-closed-loop speed control of clutch driven plate.

5.1.1. Driver Different Shifting Intentions. Driver different shifting intentions can be reflected by the throttle opening. In the case of shifting from 1st speed gear to 2 nd speed gear, the corresponding simulation results of shifting process under throttle openings of $20 \%$ and $50 \%$ are shown in Figure 6.

As shown in Figure 6(a), the engine and clutch have a higher rotate speed, a higher angular acceleration, and a shorter shifting time $(0.6064 \mathrm{~s}$, excluding the microsliding phase) under $50 \%$ throttle opening in comparison to a $20 \%$ throttle opening $(0.7162 \mathrm{~s})$; Besides, the angular acceleration deviation factor $\delta$ is 0.4 in both working conditions. With $50 \%$ throttle opening clutch 2 angular acceleration is higher, so the microsliding time is shorter and the fast shifting demands can be better satisfied under large throttle opening.

Figure 6(b) illustrates that the Shock intensity is 0 under two conditions for adopting the nonimpact shifting principle. But the vehicle Shock intensity at the synchronizing moment is relatively larger, even slightly exceeding the required standard $\left(10 \mathrm{~m} / \mathrm{s}^{3}\right)$ due to the corresponding larger acceleration deviation under a $50 \%$ throttle opening. To dig the reason more detail, the current engine torque needs to meet the driver's demand torque after synchronization. However, during this process, the Shock intensity is proportional to the changing rate of engine output torque. Thus, a larger throttle opening leads to a larger torque changing rate and a larger Shock intensity.

In Figure 6(c), the peak Shock intensity has already exceeded the maximum limitation under the 50\% throttle opening. A solution to the problem is to increase angular acceleration deviation factor $\delta$ at the sacrifice of shifting time at the synchronizing moment. As shown in Figure 6(c), the shifting time increases from $1.152 \mathrm{~s}$ to $1.24 \mathrm{~s}$ and accordingly the Shock intensity declines to the required range at the synchronizing moment after increasing $\delta$.

As shown in Figure 6(d), compared with 20\% throttle opening. The driver demands larger torque in the whole shifting process under $50 \%$ throttle opening. In addition, as the vehicle transmission ratio decreases, the clutch is required to transmit a relatively larger torque in order to realize the nonimpact shifting process. However, the engine output torque finally breaks away from the constraint of TCU torque requirements after engagement, restoring to the demanded torque level.

Figure 6(e) illustrates that a larger friction work is generated under $50 \%$ throttle opening, which is mainly caused by larger speed and torque differences between driving and driven plate (as shown in Figure 6(a) and Figure 6(d), resp.).

The variation of vehicle speed under two working conditions can be seen in Figure 6(f).

5.1.2. The Shifting Process between Different Speeds. To validate the fact that a large transmission ratio switch theoretically takes a longer shifting time, it is necessary to simulate the shifting process from 1 st to 2 nd and 3 rd to 4 th, as described in Figure 7 . The simulation is performed under $30 \%$ throttle opening and 0.4 angular acceleration deviation factor. Moreover, for convenience, different initial speeds of engine and clutch driven plate are set according to different working conditions and the shifting process is enabled after $0.4 \mathrm{~s}$ and the delayed period is used for the engagement of the synchronizer.

Figure 7 (a) shows the comparison of shifting time from 1st to 2 nd and 3rd to 4 th speed gear upshifting process, which takes $0.6738 \mathrm{~s}$ and $0.6052 \mathrm{~s}$, respectively. Besides, in the process of $3 \mathrm{rd}$ to 4 th speed gear upshifting, the initial angular acceleration should be smaller, so it needs to reduce speed deviation threshold value in (20) otherwise a too small desired angular acceleration will be generated during microsliding phase and the shifting time is prolonged.

Figure 7(b) shows a comparison in terms of Shock intensity in shifting process of 1st to 2 nd and $3 \mathrm{rd}$ to 4 th with the same angular acceleration deviation factor $\delta(0.4)$. In the process of 3rd to 4 th speed gear, the angular acceleration of clutch driven plate is relatively smaller which also means a smaller angular speed deviation between engine and clutch driven plate at the synchronizing moment. No doubt that the vehicle Shock intensity is also smaller. After synchronizing, the Shock intensity, however, is mainly determined by 


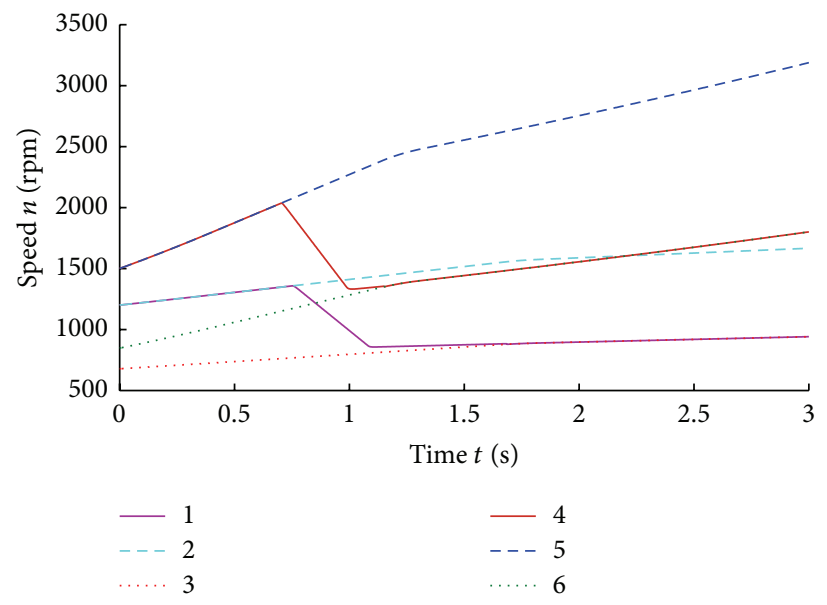

(a) The speeds of engine and clutch driven plate (1: $20 \%$ throttle opening engine speed, 2: $20 \%$ throttle opening clutch 1 driven plate speed, 3: 20\% throttle opening clutch 2 driven plate speed, $4: 50 \%$ throttle opening engine speed, 5: 50\% throttle opening clutch 1 driven plate speed, and 6: $50 \%$ throttle opening clutch 2 driven plate speed)

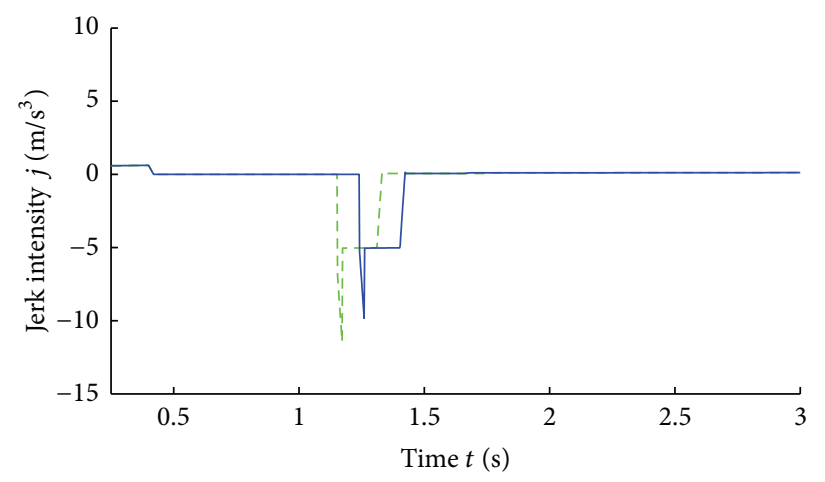

- - Angular acceleration deviation factor is 0.4

— Angular acceleration deviation factor is 0.6

(c) The influences of different angular acceleration deviation factors on Jerk intensity under 50\% throttle opening

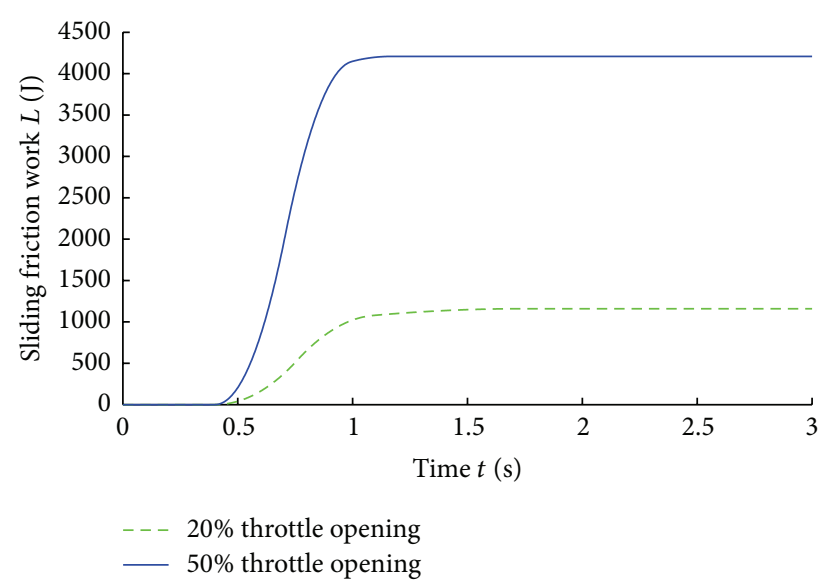

(e) Sliding friction work

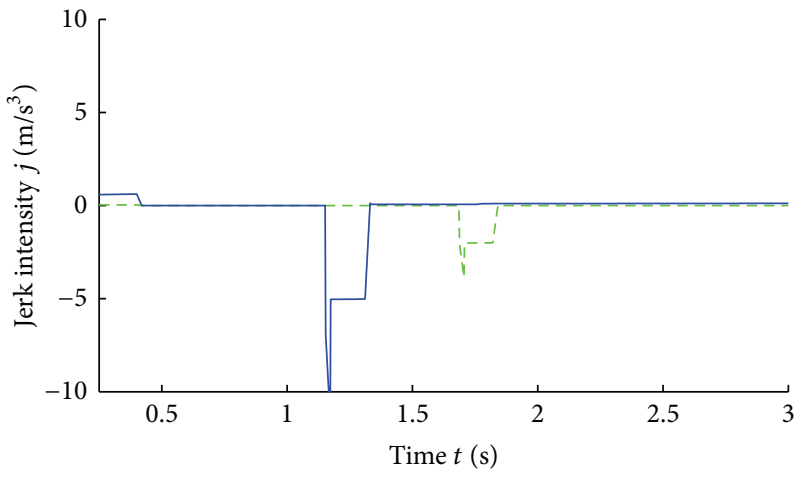

- - $20 \%$ throttle opening

— $50 \%$ throttle opening

(b) Jerk intensity

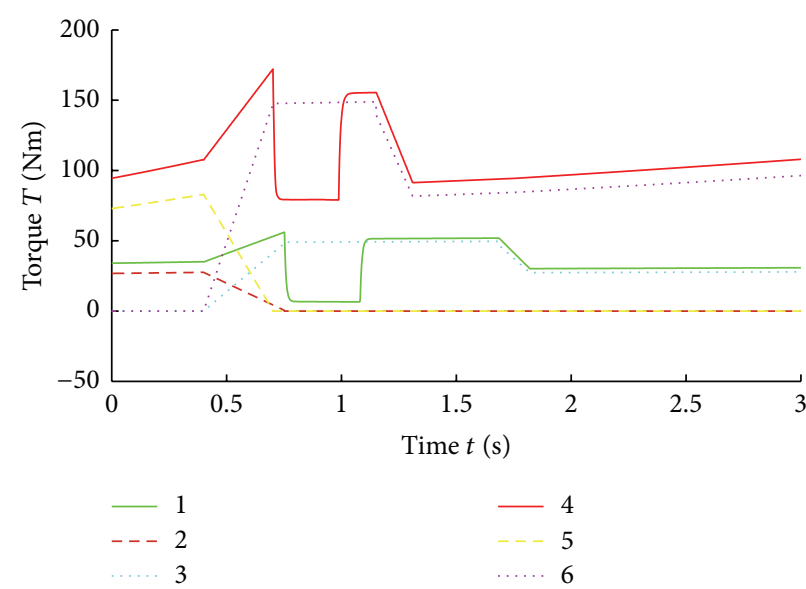

(d) The torque transferred by engine and clutch (1: $20 \%$ throttle opening engine torque, 2: $20 \%$ throttle opening clutch 1 torque, 3: $20 \%$ throttle opening clutch 2 torque, $4: 50 \%$ throttle opening engine torque, 5: 50\% throttle opening clutch 1 torque, and 6: 50\% throttle opening clutch 2 torque)

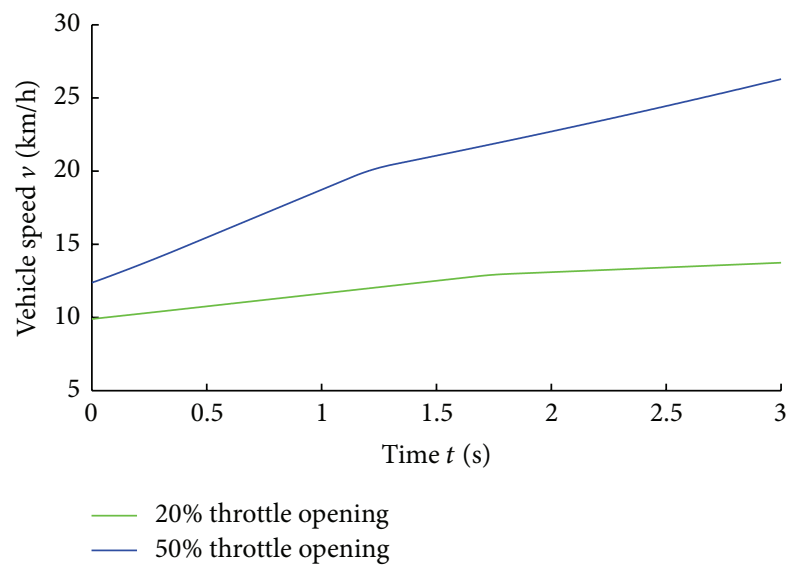

(f) Vehicle speed

FIGURE 6: Simulation results of driver different shifting intentions. 


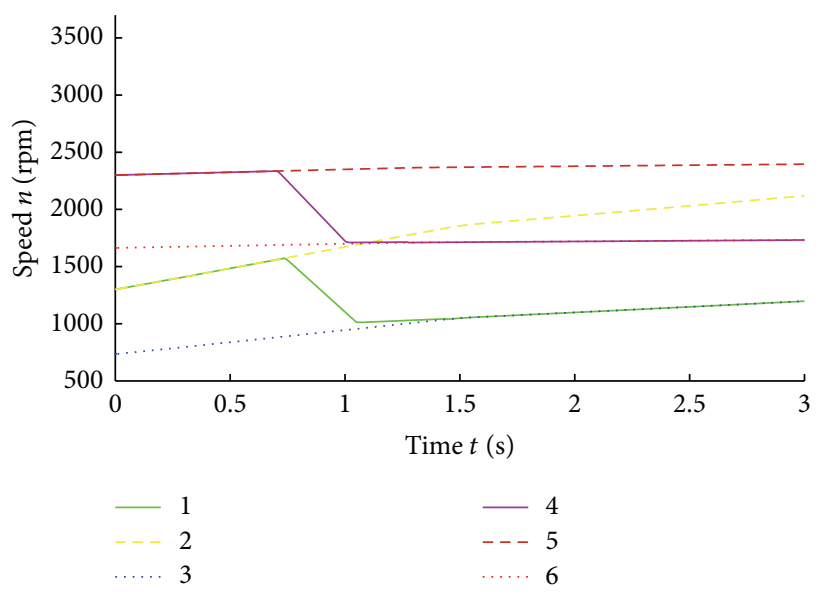

(a) Speeds of engine and clutch driven plate (1: engine speed during 1st to 2nd gear, 2: clutch 1 driven plate speed during 1st to 2nd gear, 3: clutch 2 driven plate speed during 1 st to 2 nd gear, 4 : engine speed during 3 rd to 4 th gear, 5: clutch 1 driven plate speed during 3rd to 4 th gear, and 6: clutch 2 driven plate speed during 3 rd to 4 th gear)

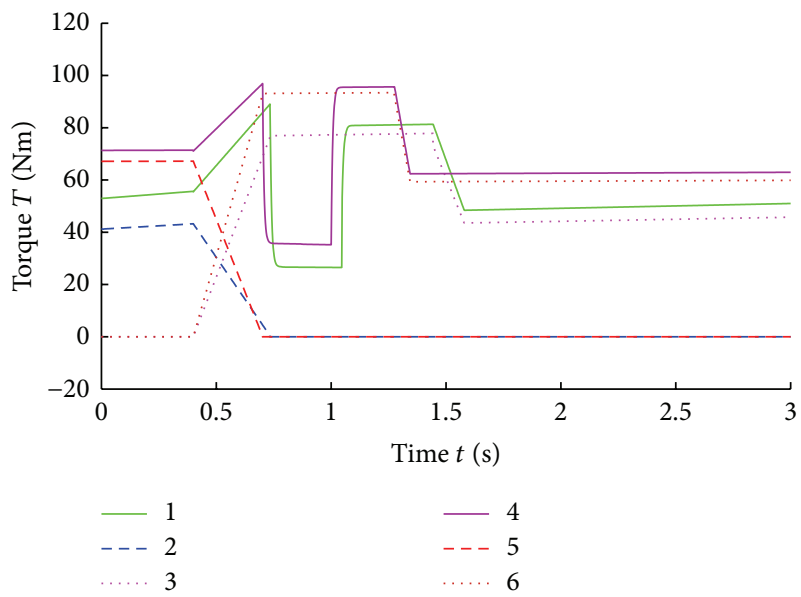

(c) Torque transferred by engine and clutch (1: engine torque during 1st to 2 nd gear, 2: clutch 1 driven plate torque during 1 st to 2 nd gear, 3 : clutch 2 driven plate torque during 1st to 2 nd gear, 4 : engine torque during 3 rd to 4 th gear, 5 : clutch 1 driven plate torque during 3 rd to 4 th gear, and 6: clutch 2 driven plate torque during 3 rd to 4 th gear)

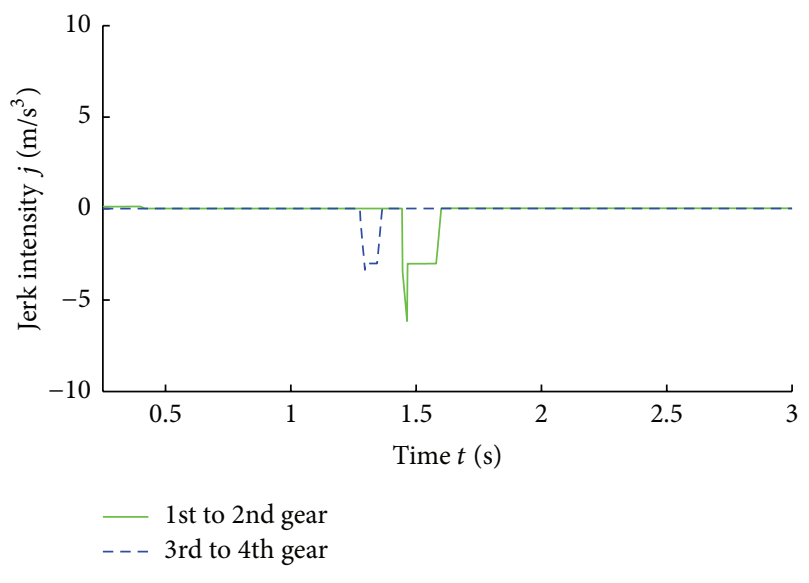

(b) Jerk intensity

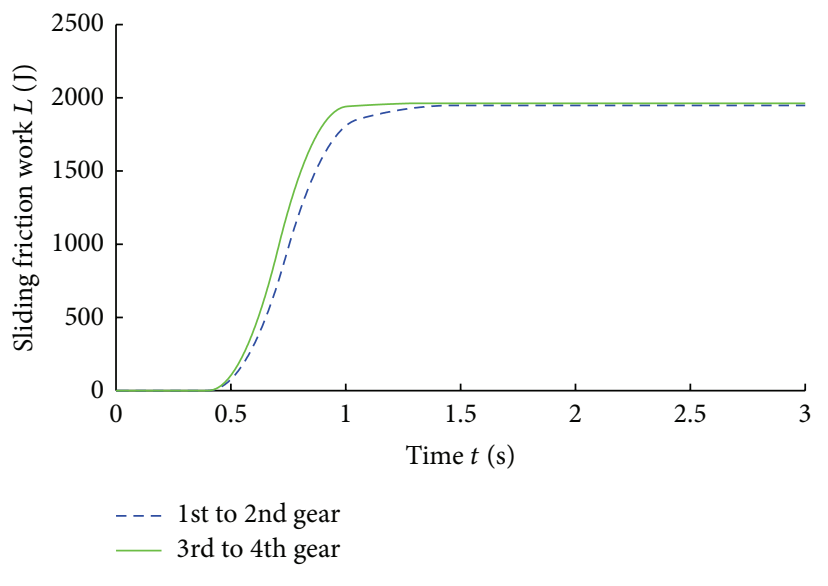

(d) Sliding friction work

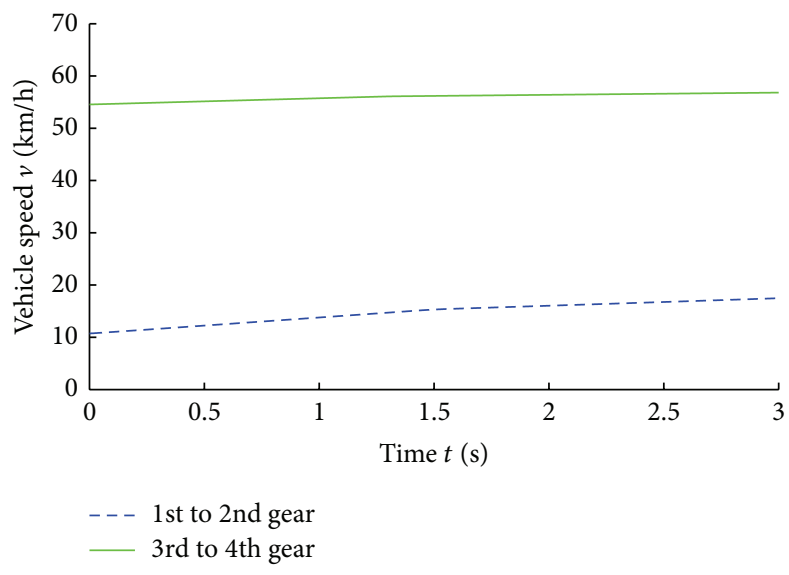

(e) Vehicle speed

FIGURE 7: Simulation results in different speed shifting. 


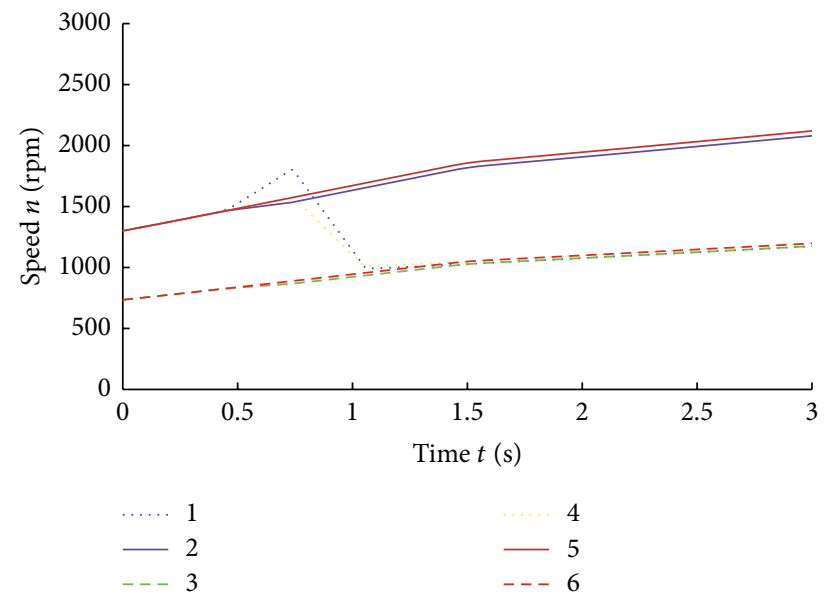

(a) Speeds of engine and clutch driven plate (1: engine speed in open-loop control, 2: clutch 1 driven plate speed in open-loop control, 3: clutch 2 driven plate speed in open-loop control, 4: engine speed after closed-loop modification, 5: clutch 1 driven plate speed after closed-loop modification, and 6: clutch 2 driven plate speed after closed-loop modification)

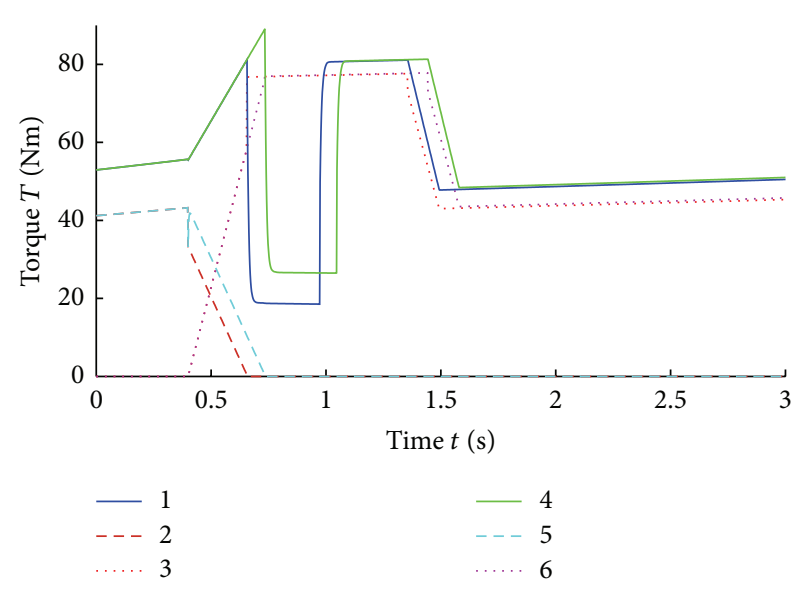

(c) Torque of engine and clutch (1: engine torque in open-loop control, 2: clutch 1 torque in open-loop control, 3: clutch 2 torque in openloop control, 4: engine torque after closed-loop modification, 5: clutch 1 torque after closed-loop modification, and 6: clutch 2 torque after closed-loop modification)

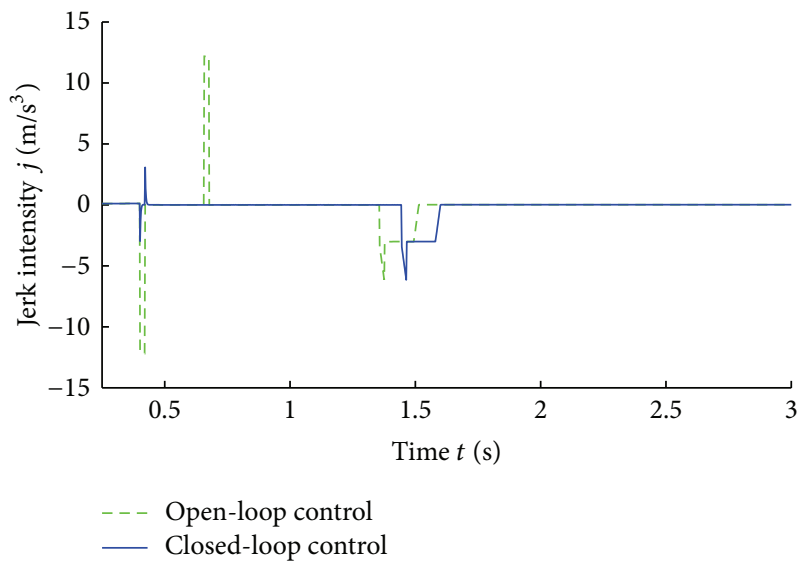

(b) Jerk intensity

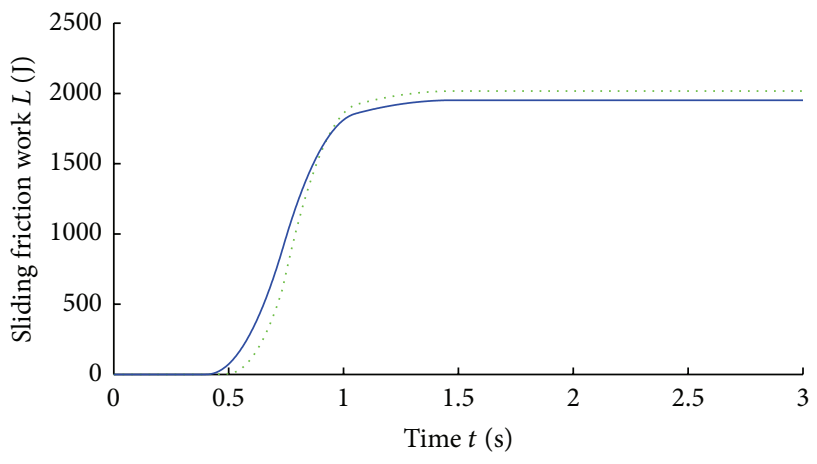

Open-loop control

Closed-loop control

(d) Sliding friction work

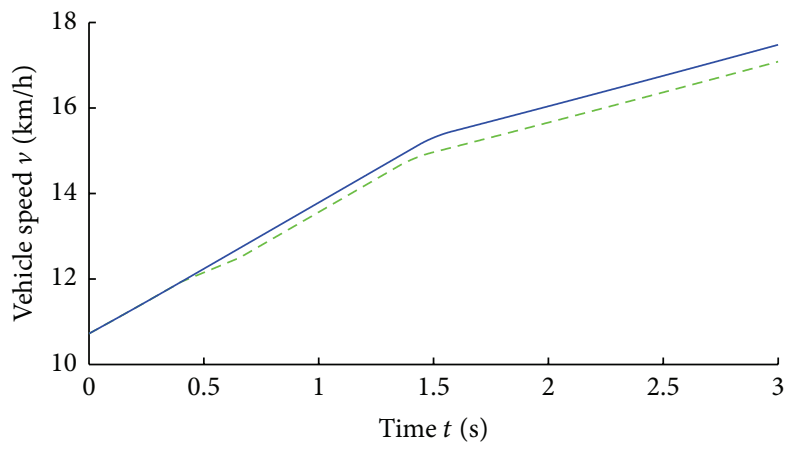

Open-loop control

— Closed-loop modification

(e) Vehicle speed

FIGURE 8: The influence of clutch torque hysteresis on control effect. 


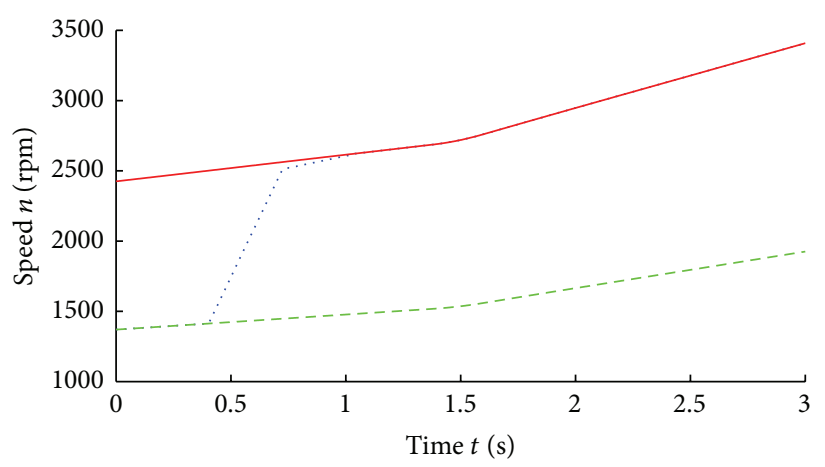

Engine speed

- Clutch 1 driven plate speed

- - Clutch 2 driven plate speed

(a) Speeds of engine and clutch driven plate

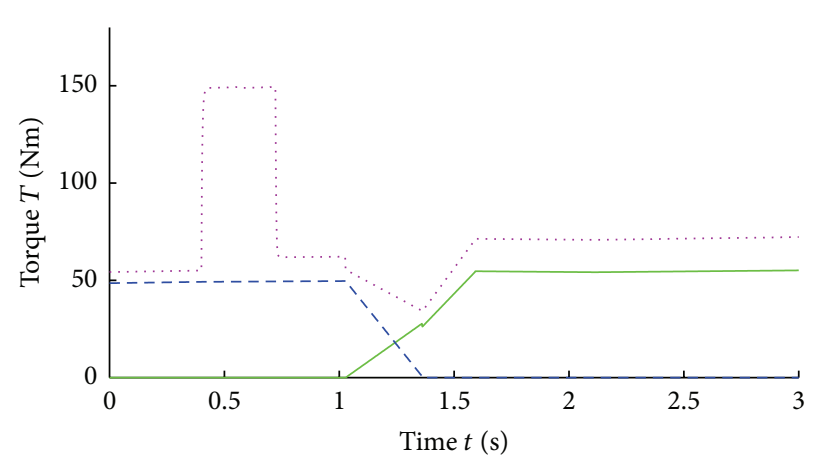

Engine torque

- Clutch 1 torque

- - - Clutch 2 torque

(c) Torque of engine and clutch

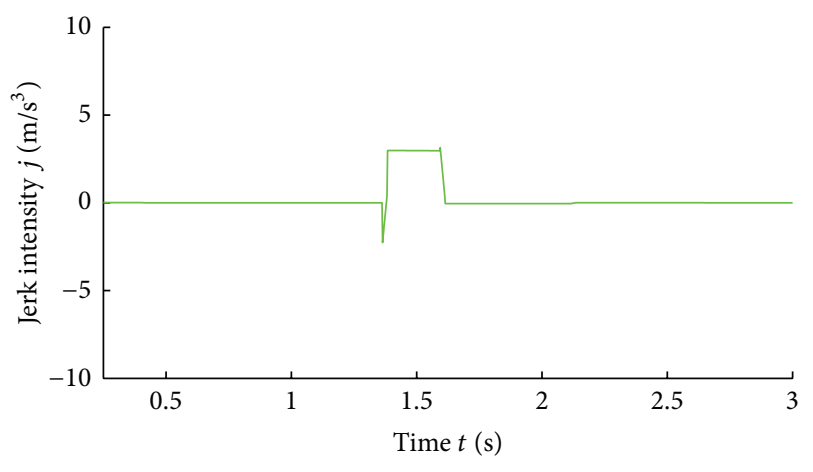

(b) Jerk intensity

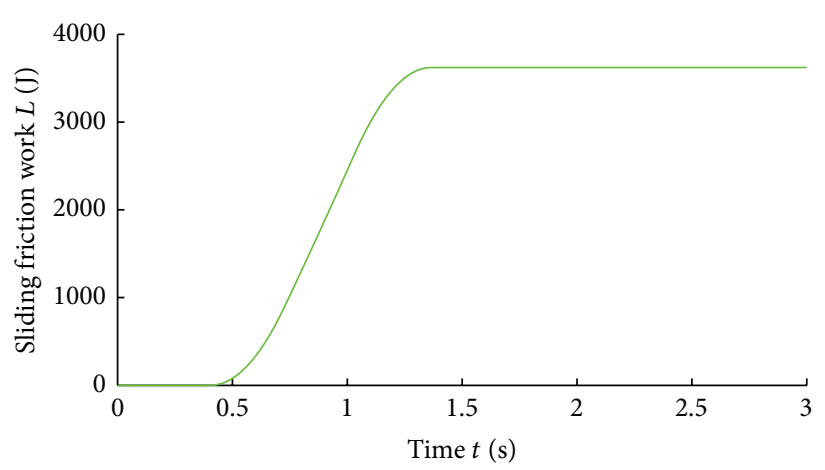

(d) Sliding friction work

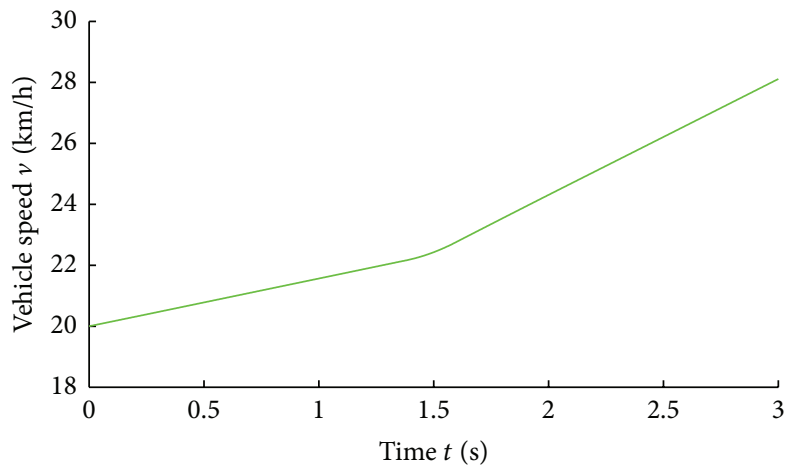

(e) Vehicle speed

FIGURE 9: Simulation results of shifting from 2nd to 1st speed gear downshifting process.

the changing rates of engine torque, so the Shock intensity holds the same value in both processes, as depicted in Figure 7(b).

A shorter time is needed in the shifting from 3rd to 4th speed gear upshifting process in comparison with the shifting from 1st to 2nd as described in Figure 7(c).

As shown in Figure 7(d), the approximately equal friction work is generated. It is mainly because the speed and torque differences between clutch driving and driven plates are almost the same in the two working conditions.
Figure 7(e) describes a relatively stable speed variation, which has no large raised or depressed curves during the shifting process in both working conditions. It indicates a smooth riding performance.

5.1.3. The Influence of Clutch Actuator's Hysteresis. Suppose that the torque transfer by clutch 2 has a $0.1 \mathrm{~s}$ delay. Under this circumstance, the open-loop control and closed-loop modification of speeds are separately simulated and analyzed, 


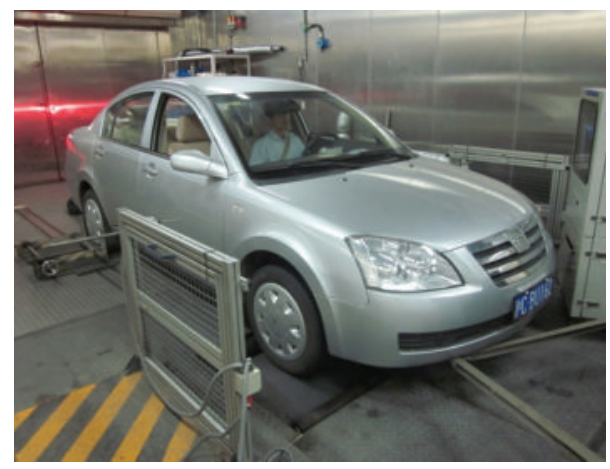

FIGURE 10: Five-speed dry DCT real vehicle chassis dynamometer test.

as depicted in Figure 8. Similarly, the attention is mainly focused on the hysteresis influence of clutch torque in torque phase.

As expressed in Figure 8(a), the existence of clutch 2 actuator's hysteresis decreases engine load-torque, which accounts for the engine speed's sharp rise in open-loop control; Moreover, because of the transmission torque reduction, the accelerations of clutch 1 and clutch 2 driven plates decrease accordingly. The influence of clutch 2 actuator's hysteresis, however, can be totally eliminated by adopting closed-loop modification.

As depicted in Figure 8(b), clutch 2 actuator's torque hysteresis also causes the variation of vehicle acceleration, which gives reasons for the large vehicle Shock intensity at the beginning of torque phase and after torque phase. The Shock intensity can be narrowed in a relatively small range by introducing closed-loop modification, which consequently increases the shifting-fell and riding comfort a lot.

As shown in Figure 8(c), at the beginning of torque phase, the torque clutch 2 transfer has a $0.1 \mathrm{~s}$ delay, therefore inducing the speed variation of clutch 2's driven plate, which can only be compensated by decreasing control accuracy and effect. The use of closed-loop modification, however, basically removes the torque hysteresis, restoring clutch 2's actual torque to its original value.

Figure 8(d) illustrates the friction work generated under two types of control methods is similar. That is because the existence of the hysteresis of clutch 2's actuator, to some extent, decreases the actual transferred torque, but meanwhile, the speed error between driving and driven plates is enlarged. So the gross friction work varies hardly.

Figure 8(e) shows the vehicle speed. Due to the existence of torque hysteresis transferred by clutch, the introducing of closed-loop modification control is advantageous for the control accuracy and the shifting feeling of vehicle.

5.2. Simulation of Down Shifting Process. As the up and downshifting process is similar, a brief simulation is shown in terms of shifting from 2 nd to 1st speed gear downshifting process with the assumptions of $30 \%$ throttle opening and $20 \mathrm{~km} / \mathrm{h}$ initial vehicle speed, which is depicted in Figure 9.

As shown in Figures 9(a) and 9(c), the downshifting process begins at $0.4 \mathrm{~s}$, which starts with an inertia phase.
In this phase clutch 1 transmits zero torque while clutch 2 gradually slips to the sliding-friction-position and transmits an invariant torque. Meanwhile, in order to be synchronized rapidly between engine and clutch 1 , the engine torque needs be actively adjusted. As the speed differences between engine and clutch 1 driven plate reach a certain threshold, it turns to microsliding friction stage. The engine torque decreases and the angular acceleration of engine output shaft reduces correspondingly, which can guarantee a minor angular acceleration error of the clutch 1 driven plate at the synchronizing moment. After that, a torque phase is followed. In this phase, clutch 2 transmits a gradually declined torque, while clutch 1 transmits a rising torque. The torque changing rule of clutch meets a certain relationship, which ensures the vehicle has a constant acceleration. In the end, the engine output torque gradually comes to the driver demand; therefore the vehicle acceleration is varied slowly.

Figures 9(a), 9(b), and 9(e) indicate that the Shock intensity maintains zero in the downshifting process, though vibrating a little at the synchronizing moment, which satisfies the required standard. In addition, the shifting time is comparatively rational. With a small friction power, it can be completely accepted. The vehicle speed varies smoothly and the shifting comfort is also comparatively well.

The simulation analysis of upshifting and downshifting process illustrates that the proposed model-based torque coordinating control strategy can not only satisfy each index of the shifting quality, but also well adapt to driver shifting intentions and different speed gears shifting. Besides, the control strategy can solve the control error caused by the clutch actuator's hysteresis and external disturbance efficiently. To some degree, the system has a good robustness.

\section{The Dry DCT Real Vehicle Chassis Dynamometer Test}

Based on the simulation result, the MAP related to starting control strategy of DCT real vehicle is recalibrated. The real dry DCT vehicle chassis dynamometer test is performed based on NEDC after completing development of the DCT software. The test picture and NEDC test results are shown in Figures 10 and 11, respectively.

Figures 11(e) and 11(i) shows that, in the continuous shifting process of DCT vehicle under the NEDC driving condition, the impact degree is $j \leq 10 \mathrm{~m} / \mathrm{s}^{3}$ and the shifting time remains less than $0.8 \mathrm{~s}$, which prove that the proposed shifting control strategy can ensure the shifting smoothness and realize the fast and reliable shifting. Moreover, making an analysis of Figures 11(g), 11(h), 11(i), 11(j), 11(k), and 11(l), a conclusion can also be drawn that each speed gear and its synchronizer strictly satisfy the transmission relationship expressed in Figure 1, and depending on the switch of dual clutches' position, the five-speed dry DCT accomplishes the shifting process when the target gear synchronizer is already preengaged in advance.

As can be seen from Figures 12(a)-12(c), when the vehicle shifts from 1 st gear to 2 nd gear with a less than $50 \%$ throttle opening, the shifting time is $0.74 \mathrm{~s}$ and Jerk intensity is below 


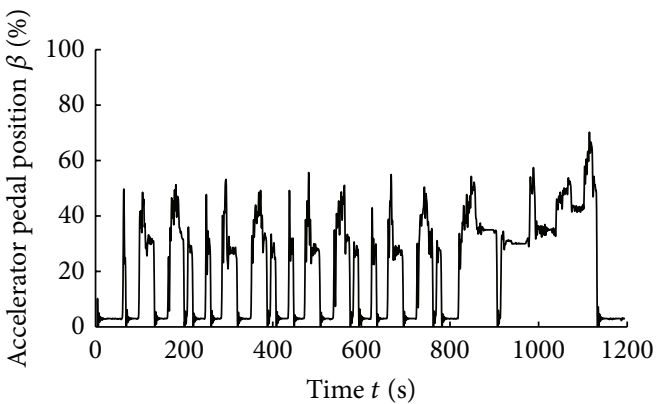

(a) Throttle opening

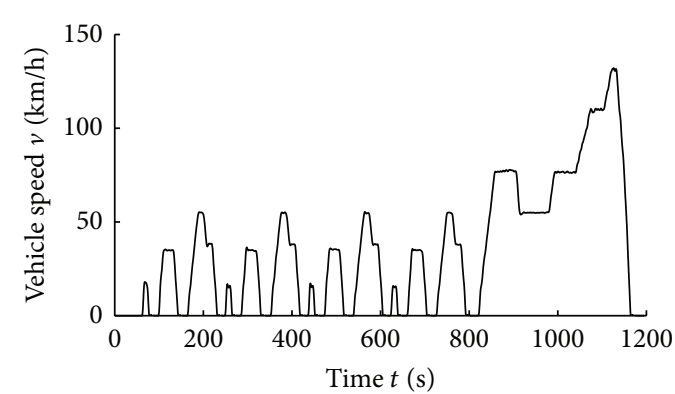

(c) Vehicle speed

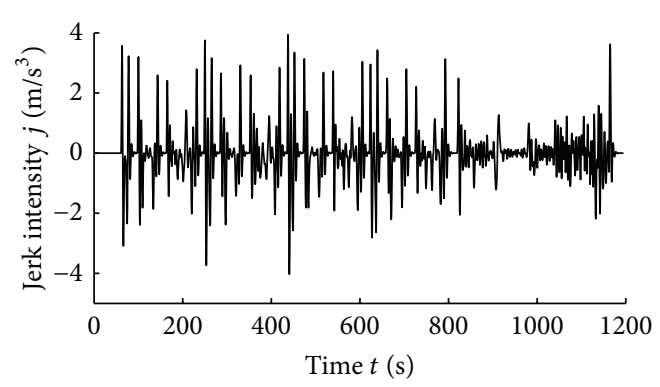

(e) Jerk intensity

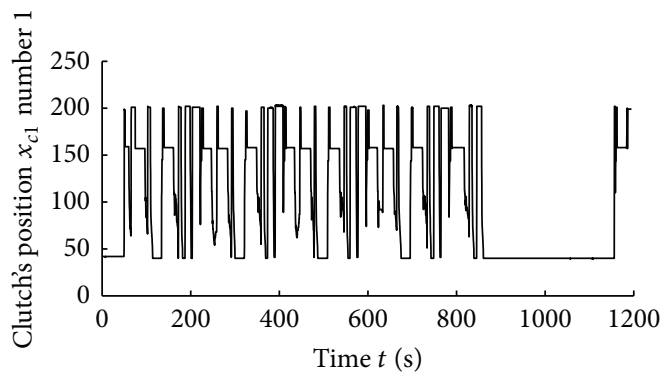

(g) Clutch's position number 1

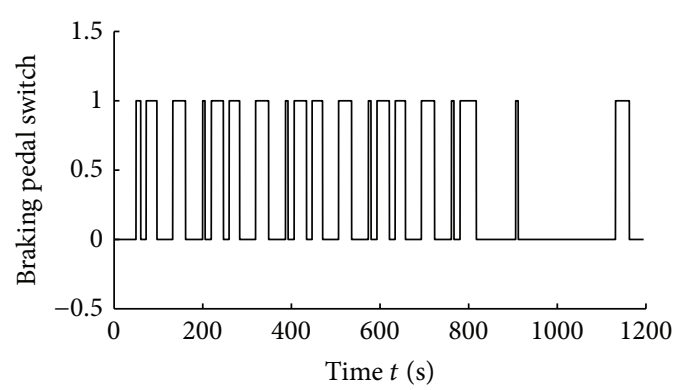

(b) Braking pedal switch

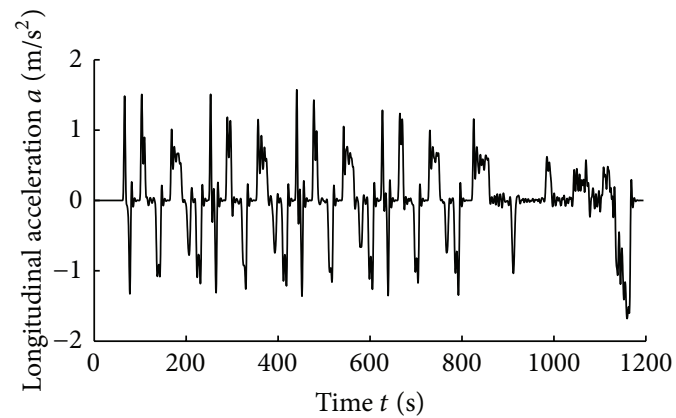

(d) Longitudinal acceleration

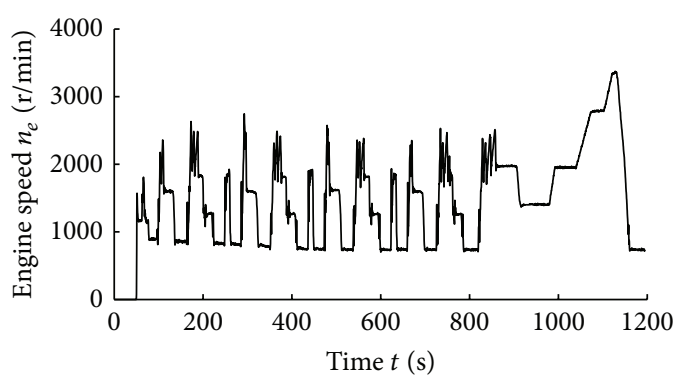

(f) Engine speed

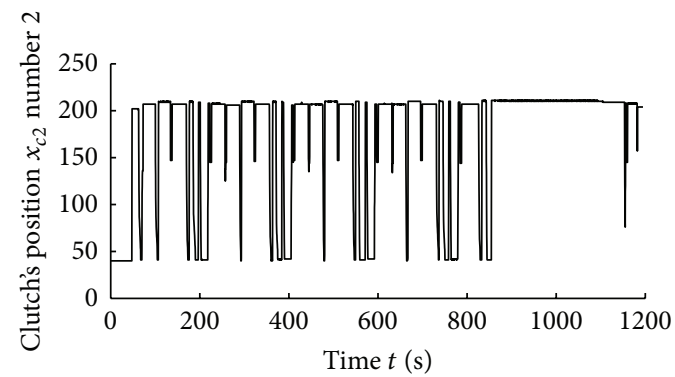

(h) Clutch's position number 2

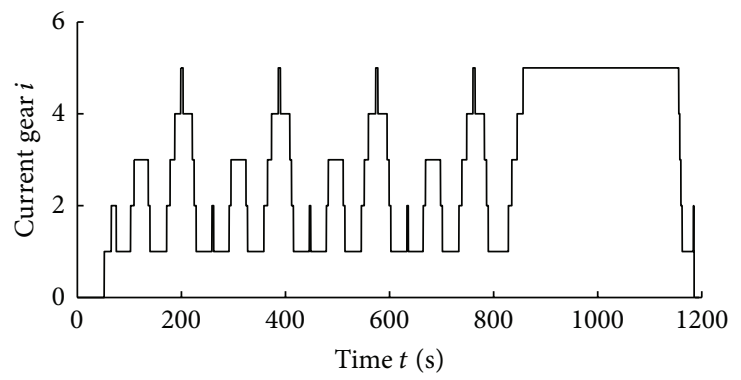

(i) Current gear

FIgURE 11: Continued. 


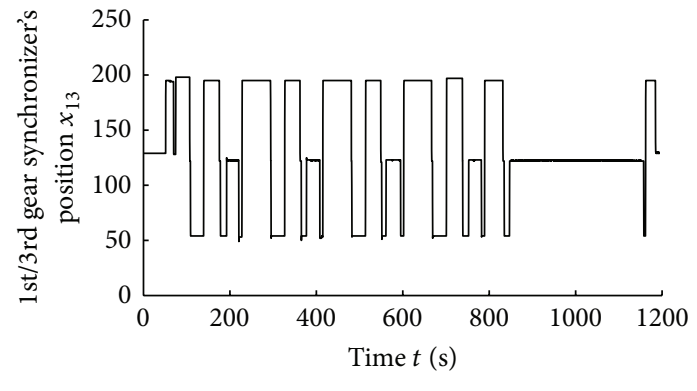

(j) 1st/3rd gear synchronizer's position

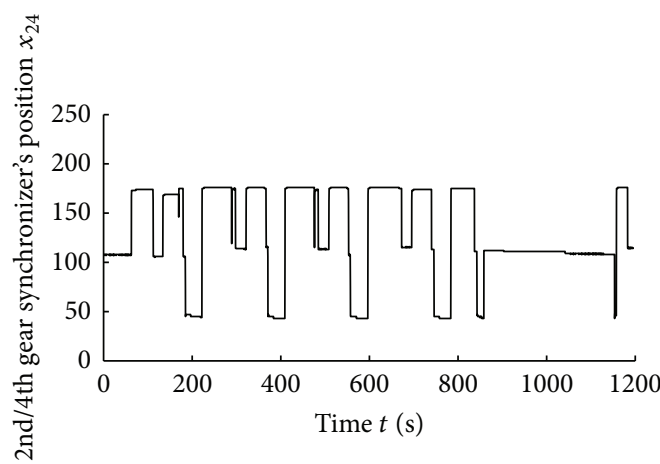

(k) 2nd/4th gear synchronizer's position

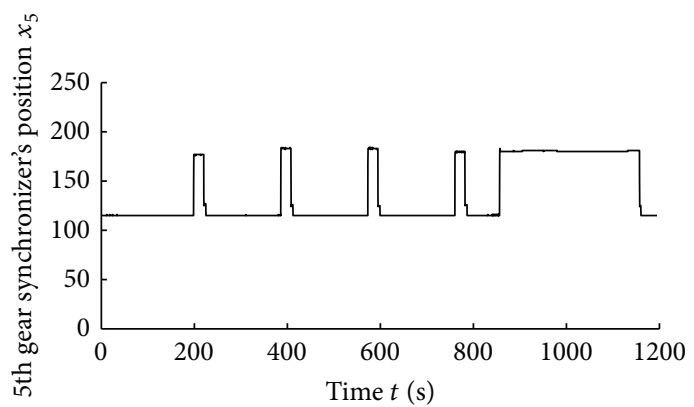

(1) 5th gear synchronizer's position

FIGURE 11: DCT sample vehicle revolving drum test based on NEDC.

$6 \mathrm{~m} / \mathrm{s}^{3}$; thus the shifting quality is effectively guaranteed. Besides, the trend of engine speed as shown in Figure 12(d) is consistent with the upshifting characteristic described in Figure 4 and the simulation result in Figure 6(a), which validate the effectiveness of the proposed control strategies.

\section{Conclusions}

Consider the following.

(1) The control objectives of the shifting process are proposed. Based on the analysis of torque and speed characteristics of engine and dual clutches during the shifting process, the fuzzy time decision and the model-based torque coordinating control strategy are proposed. The shifting quality of prototype car with DCT has been simulated under different driving conditions on the Matlab/Simulink software platform. Experimental results show that the shifting control strategy proposed in this paper can not only meet the shifting quality requirements and adapt to the various shifting conditions, but also effectively reduce the control error caused by the factors such as the hysteresis of clutch actuator and external interferences. Besides, the shifting control strategy has strong robustness.

(2) The five-speed dry DCT real vehicle chassis dynamometer test based on NEDC illustrates that the dry DCT can realize power shifting and improve shifting quality, thus the effectiveness and feasibility of fuzzy time decision and the model-based torque control strategy are valuable.

\section{Notation}

$I_{e}$ : Equivalent moment of inertia of engine crankshaft (including flywheel) and clutch driving plate

$I_{c 1}$ : Equivalent moment of inertia of clutch 1 driven plate, transmission input shaft number 1 (solid part), and relevant odd number gears

$I_{c 2}$ : Equivalent moment of inertia of clutch 2 driven plate, transmission input shaft number 2 (hollow part), and its relevant even number speed gears

$I_{m}$ : Equivalent moment of inertia of transmission intermediate shaft and its relevant gears final drive driving part

$I_{s}:$ Equivalent moment of inertia of final drive driven part, differential gears, axle shafts, wheels, and complete vehicle, which are equally converted into transmission output shaft

$b_{e}$ : Rotating viscous damping coefficient of engine output shaft

$b_{c 1}$ : Rotating viscous damping coefficient of transmission input shaft number 1

$b_{c 2}$ : Rotating viscous damping coefficient of transmission input shaft number 2 


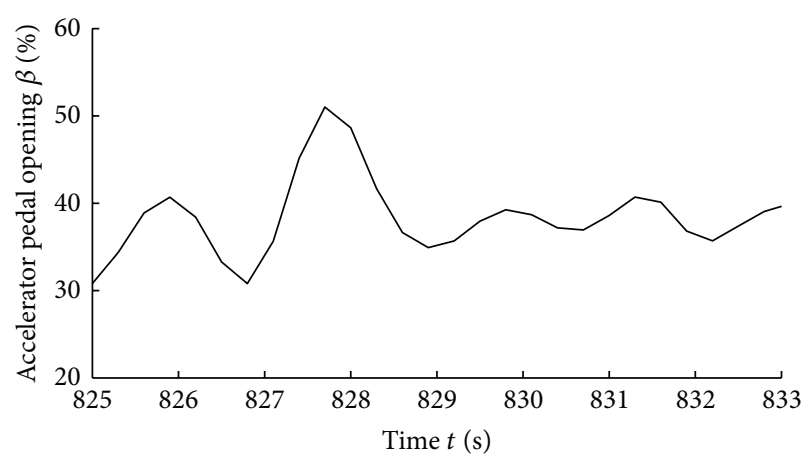

(a) Accelerator pedal opening

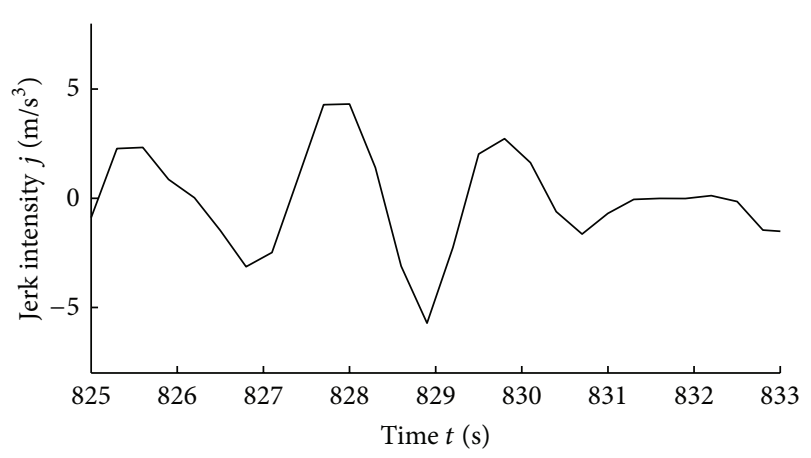

(c) Jerk intensity

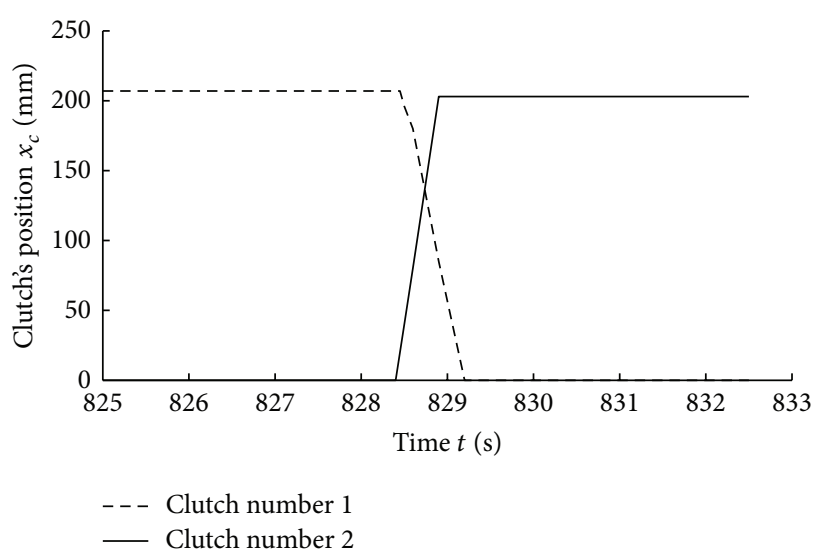

(b) Clutch's position

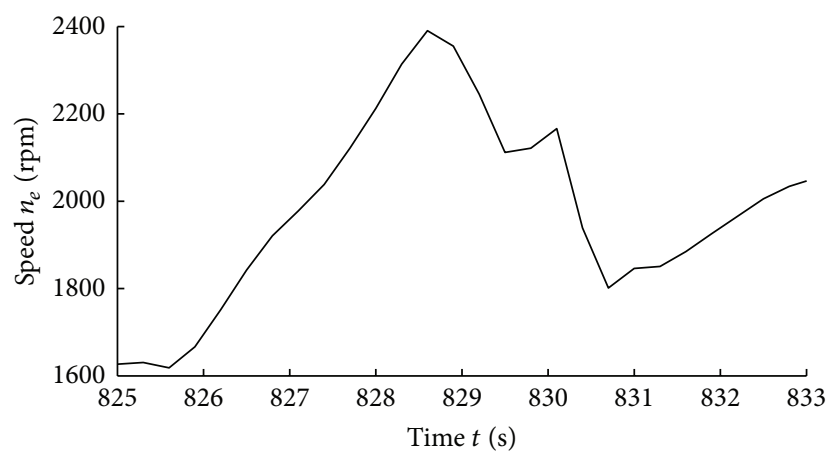

(d) Engine speed

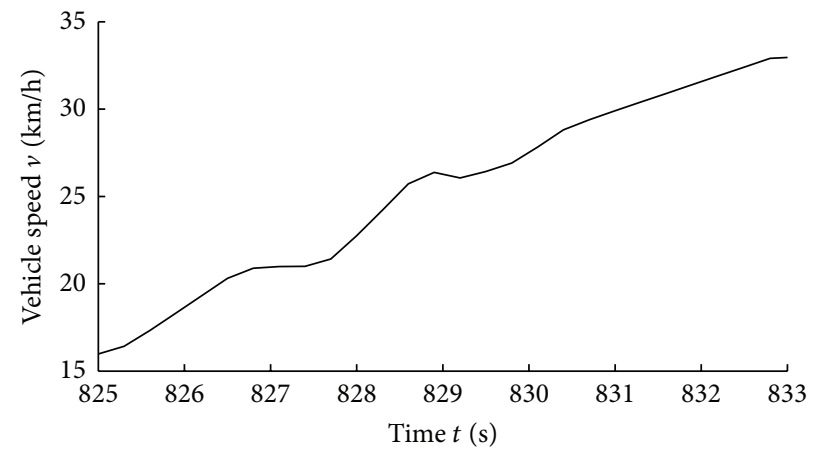

(e) Vehicle speed

FIGURE 12: 1st to 2 nd gear shifting process under suburban driving condition.

$b_{m}$ : Rotating viscous damping coefficient of transmission intermediate shaft

$b_{s}$ : Equivalent rotating viscous damping coefficient of axle shafts and wheels, which are equally converted into transmission output shaft

$\omega_{e}$ : Angular speed of engine crankshaft

$\omega_{c 1}$ : Angular speed of clutch 1 driven plate (or transmission input shaft number 1)

$\omega_{c 2}$ : Angular speed of clutch 2 driven plate (or transmission input shaft number 2)

$\omega_{m}$ : Angular speed of transmission intermediate shaft

$\omega_{s}$ : Angular speed of transmission output shaft $\omega_{w}$ : $\quad$ Angular speed of wheels, which are equally converted into transmission output shaft

$T_{e}$ : $\quad$ Engine output torque

$T_{f}$ : Driving resistance torque which is equally converted into transmission output shaft

$T_{c 1}, T_{c 2}: \quad$ Transfer torque of clutch 1 and clutch 2

$T_{c m 1}, T_{c m 2}$ : Torque of transmission input shafts number 1 and number 2 acting on intermediate shaft

$T_{m c 1}, T_{m c 2}$ : Torque of transmission intermediate shaft reacting on input shafts number 1 and number 2

$I_{g 1}, I_{g 3}, I_{g r}:$ Moments of inertia of 1st, 3rd, and reverse driven gears 


\begin{tabular}{|c|c|}
\hline$I_{g 2}, I_{g 4}, I_{g 5}:$ & $\begin{array}{l}\text { Moments of inertia of } 2 \mathrm{nd}, 4 \mathrm{th} \text {, and } 5 \text { th } \\
\text { driving gears }\end{array}$ \\
\hline$i_{1} \sim i_{5}, i_{a}:$ & Forward gear ratios and final drive ratio \\
\hline$r:$ & The radius of wheel \\
\hline$\alpha:$ & Engine throttle position \\
\hline$f\left(\alpha, \omega_{e}\right):$ & Engine output torque nonlinear function \\
\hline$\eta:$ & $\begin{array}{l}\text { Transmission efficiency of transmission } \\
\text { shafts and final drive }\end{array}$ \\
\hline$\mu_{1}, \mu_{2}:$ & $\begin{array}{l}\text { Kinetic friction coefficient among friction } \\
\text { plates of clutch } 1 \text { and clutch } 2\end{array}$ \\
\hline$R_{0}, R_{1}:$ & $\begin{array}{l}\text { Internal and external radius of friction } \\
\text { plates of clutch }\end{array}$ \\
\hline$x_{1}, x_{2}:$ & Displacement of clutch 1 and clutch 2 \\
\hline$F\left(x_{1}\right), F\left(x_{2}\right):$ & $\begin{array}{l}\text { Positive pressure function of pressure plate } \\
\text { of clutch } 1 \text { and clutch } 2\end{array}$ \\
\hline$T_{c 1}^{L}, T_{c 2}^{L}:$ & $\begin{array}{l}\text { Transfer torque after full engaging of } \\
\text { clutch which is determined by the engine } \\
\text { torque, speed, and vehicle resistance } \\
\text { torque }\end{array}$ \\
\hline$m:$ & Mass of vehicle \\
\hline$g:$ & Acceleration of gravity \\
\hline$f:$ & Rolling resistance coefficient \\
\hline$v:$ & Vehicle velocity \\
\hline$C_{d}:$ & Wind drag coefficient \\
\hline A: & Windward area \\
\hline$\theta:$ & Slope angle \\
\hline$\delta:$ & Correction coefficient of rotating mass. \\
\hline
\end{tabular}

\section{Conflict of Interests}

The authors declare that there is no conflict of interests regarding the publication of this paper.

\section{References}

[1] X. X. Guo, C. Fu, F. Cheng et al., "Modeling and simulation research of dual clutch based on fuzzy control," SAE Paper 200701-3754, 2007.

[2] M. Kulkarni, T. Shim, and Y. Zhang, "Shift dynamics and control of dual-clutch transmissions," Mechanism and Machine Theory, vol. 42, no. 2, pp. 168-182, 2007.

[3] Y. Zhang, X. Chen, X. Zhang, H. Jiang, and W. Tobler, "Dynamic modeling and simulation of a dual-clutch automated lay-shaft transmission," Journal of Mechanical Design, Transactions of the ASME, vol. 127, no. 2, pp. 302-307, 2005.

[4] M. Goetz, M. C. Levesley, and D. A. Crolla, "Integrated powertrain control of gearshiftings on twin clutch transmissions," SAE Paper 2004-01-1637, 2004.

[5] M. Goetz, M. C. Levesley, and D. A. Crolla, "Dynamics and control of gearshifts on twin-clutch transmissions," Automobile Engineering, vol. 219, no. 8, pp. 951-963, 2005.

[6] D.-T. Qin, Y.-S. Zhao, J.-J. Hu, and M. Ye, "Analysis of shifting control for dry dual clutch system," Journal of Chongqing University, vol. 32, no. 9, pp. 1016-1022, 2009.

[7] M. K. Niu, X. H. Cheng, B. Z. Gao et al., "A study on shifting characteristics of dual clutch transmission," Automotive Engineering, vol. 6, no. 4, pp. 453-459, 2004.
[8] G. Q. Wu and D. M. Zhan, "A research on the way of clutch actuation during DCT upshifting based on optimality theory," Automotive Engineering, vol. 31, no. 3, pp. 258-261, 2009.

[9] Y. T. Li, Z. G. Zhao, and T. Zhang, "Research on optimal control of twin clutch engagement pressure for dual clutch transmission," China Mechanical Engineering, vol. 21, no. 12, pp. 1496-1501, 2010.

[10] Z. G. Zhao and J. H. Qiu, " $H_{\infty}$ robust control for twin clutches of DCT during vehicle's starting and shifting processes," China Mechanical Engineering, vol. 23, no. 6, pp. 745-751, 2012.

[11] A. L. Ge and J. Q. Wu, "Research on optimizing engagedschedule of clutch," Automotive Engineering, vol. 10, no. 2, pp. 54-65, 1988.

[12] Y. G. Liu, Study on Integrated Control of Passenger Vehicles Equipped With Dual Clutch Transmission, Chongqing University, Chongqing, China, 2010.

[13] J. Zhu, Fuzzy Control and System Theory, Machinery Industry Press, Beijing, China, 2005.

[14] H. Zhang, Y. Shi, and A. Saadat Mehr, "On $H_{\infty}$ filtering for discrete-time takagi-sugeno fuzzy systems," IEEE Transactions on Fuzzy Systems, vol. 20, no. 2, pp. 396-401, 2012. 


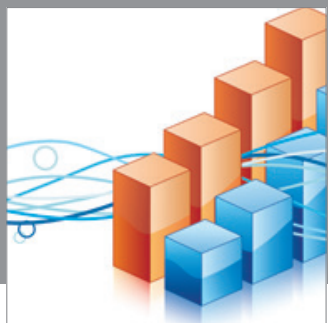

Advances in

Operations Research

mansans

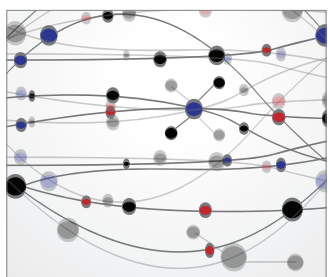

The Scientific World Journal
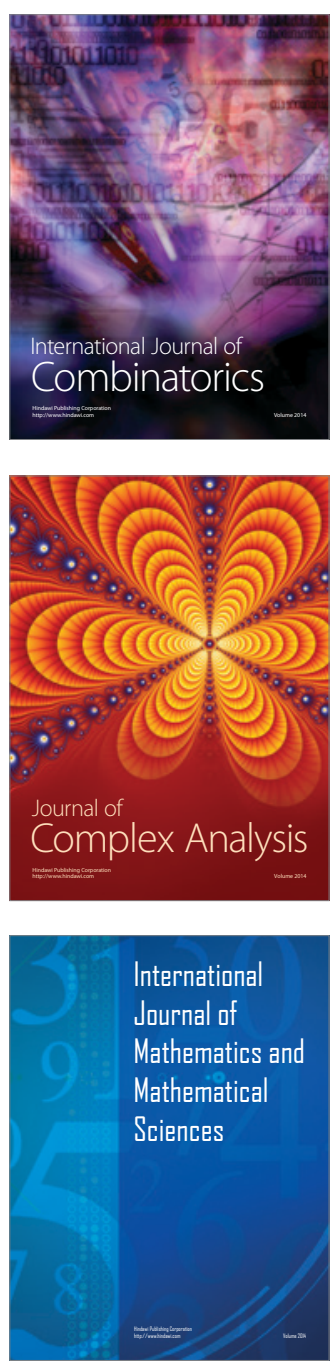
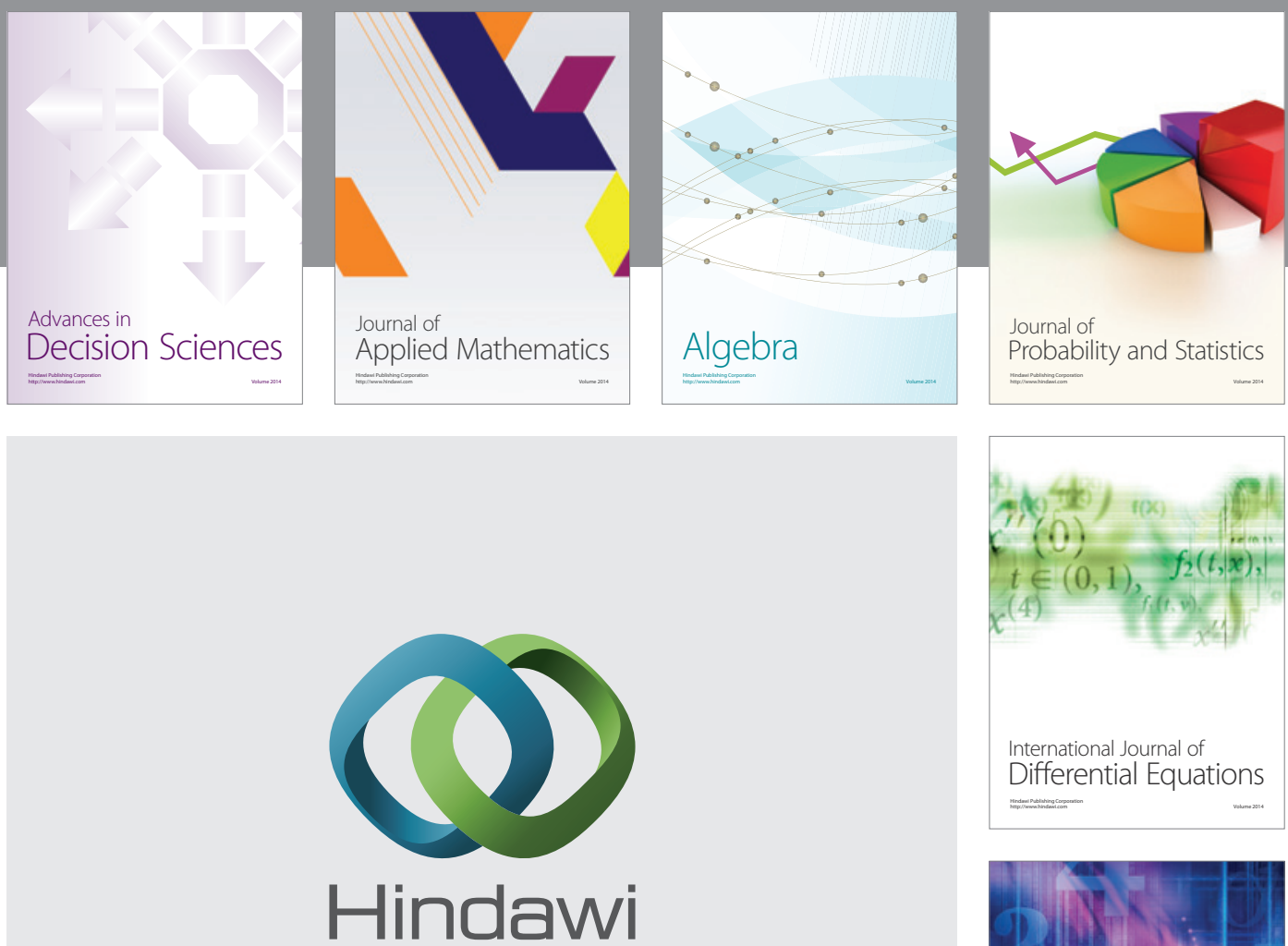

Submit your manuscripts at http://www.hindawi.com
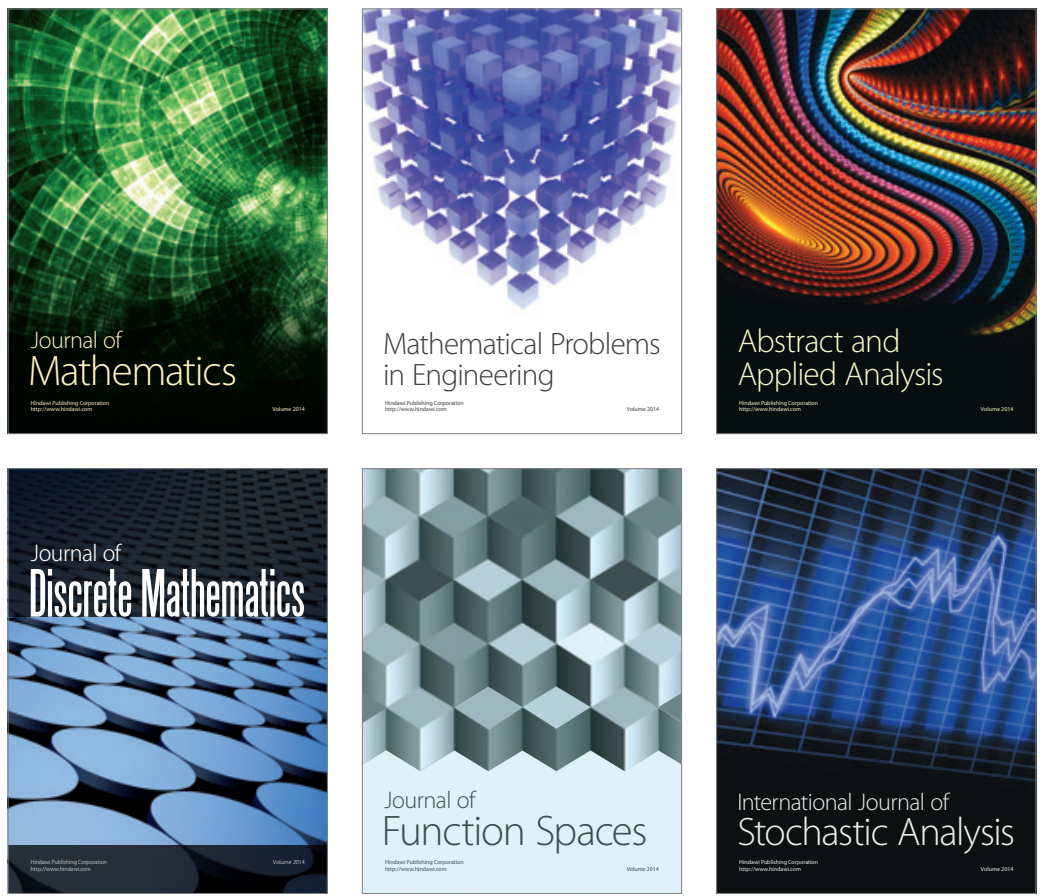

Journal of

Function Spaces

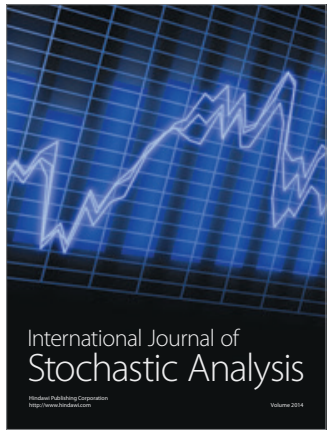

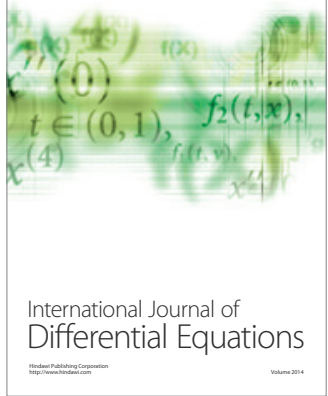
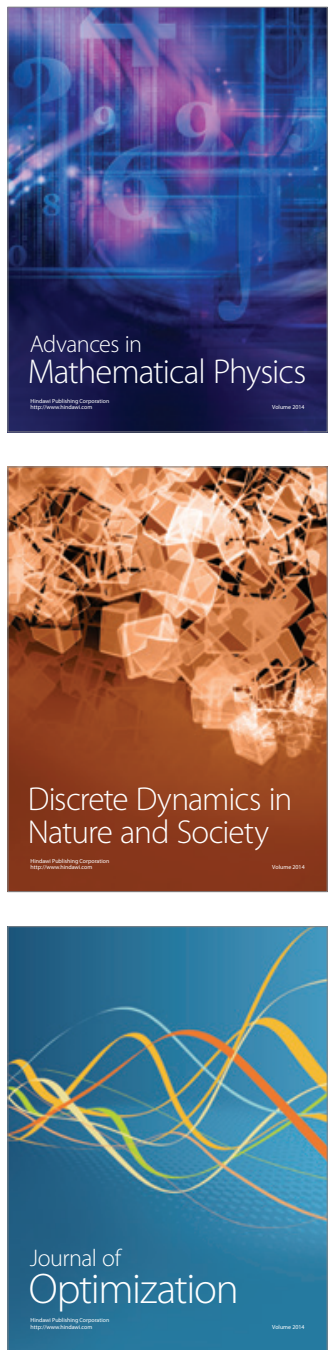